\title{
National Calibration Facility for Retroreflective Traffic Control Materials - Phase I
}

C. Cameron Miller Todd Heimer

Edward Early 


\title{
National Calibration Facility for Retroreflective Traffic Control Materials - Phase I
}

\author{
C. Cameron Miller \\ Todd Heimer \\ Edward Early \\ Optical Technology Division \\ Physics Laboratory
}

Sponsored by The American Association of State Highway and Transportation Officials In cooperation with The Federal Highway Administration Conducted in The National Cooperative Highway Research Program Administered by The Transporation Research Board of the National Research Council

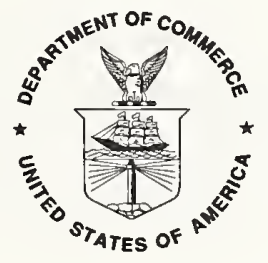

U.S. Department of Commerce Donald L. Evans, Secretary

Technology Administration Phillip J. Bond, Under Secretary for Technology 
Certain commercial entities, equipment, or materials may be identified in this document in order to describe an experimental procedure or concept adequately. Such identification is not intended to imply recommendation or endorsement by the National Institute of Standards and Technology, nor is it intended to imply that the entities, materials, or equipment are necessarily the best available for the purpose. 


\section{PREFACE}

On December 12, 2001 the National Cooperative Highway Research Program (NCHRP) awarded NCHRP Project 05-16, "National Calibration Facility for Retroreflective Traffic Control Materials" to the Optical Technology Division of the National Institute of Standards and Technology. Administered by the Transportation Research Board (TRB) and sponsored by the member departments (i.e., individual state departments of transportation) of the American Association of State Highway and Transportation Officials (AASHTO), in cooperation with the Federal Highway Administration (FHWA), the National Cooperative Highway Research Program was created in 1962 to conduct research in acute problem areas that affect highway planning, design, construction, operation and maintenance.

The state departments of transportation are the sole sponsors of the NCHRP. Support is voluntary and funds are drawn from the states' Federal-Aid Highway apportionment of State Planning and Research (SPR) funds. Furthermore, the funds can be spent only for the administration of problems approved on ballot by at least two-thirds of the states. Each state's allocation amounts to 5 and $1 / 2$ percent of its SPR apportionment and is set forth in supplementary tables issued with each year's Federal-Aid Highway apportionments.

Retroreflective devices, which return light rays preferentially in directions close to the light source, are widely used for nighttime visibility and safety. Congress has directed the Department of Transportation to establish "a standard for a minimum level of retroreflectivity that must be maintained for pavement markings and signs which apply to all roads open to public travel." Establishing a national standard for minimum levels of retroreflectivity will require accurate methods to measure retroreflectivity. Instruments are commercially available for measuring the retroreflectivity of signs and markings, and documentary standards establish procedures for such measurements. However, there can be significant variability between instruments measuring the same object, and the standards do not ensure accuracy of the instruments. There are currently no methods in the United States to determine the accuracy of measurements since national calibration standards for retroreflectivity do not exist.

This research of Project 05-16 is intended to develop a dedicated reference instrument to provide national calibration standards for retroreflectivity, thereby improving the accuracy of measurements made by other instruments. This reference instrument will use modern instrumentation techniques to perform calibrations in compliance with all relevant documentary standards. The instrument will have sufficient flexibility to accurately measure spectral and luminous quantities of both signs and markings over the full range of angles, and will have the best possible accuracy.

This document is the interim report required by the NCHRP to detail the plans for construction of the reference retroreflectometer and to validate the expected positioning uncertainty in the proposed plans. The NCHRP requires the statement of Acknowledgement of Sponsorship and Disclaimer presented below. 


\section{ACKNOWLEDGEMENT OF SPONSORSHIP}

This work was sponsored by the American Association of State Highway and Transportation Officials, in cooperation with the Federal Highway Administration, and was conducted in the National Cooperative Highway Research Program, which is administered by the Transportation Research Board of the National Research Council.

\section{DISCLAIMER}

This is an uncorrected draft as submitted by the research agency. The opinions and conclusions expressed or implied in the report are those of the research agency. They are not necessarily those of the Transportation Research Board, the National Research Council, the Federal Highway Administration, the American Association of State Highway and Transportation Officials, or the individual states participating in the National Cooperative Highway Research Program. 


\begin{abstract}
Congress has directed the United States Department of Transportation to establish "a standard for a minimum level of retroreflectivity that must be maintained for pavement markings and signs which apply to all roads open to public travel." Presented are the preliminary plans for the National Calibration Facility for Retroreflective Traffic Control Materials. Stated is the problem statement along with the research approach for solving this problem. The requirements for the reference retroreflectometer are based on information collected from national and international standards and from meetings with various people knowledgeable in the field of retroreflective measurements.

The reference retroreflectometer plans include a discussion of the design of the source, the goniometer and the detectors. Most importantly, an in-depth description of how the reference retroreflectometer will be aligned and absolutely calibrated for $\left(\alpha, \beta_{1}, \beta_{2}, \varepsilon\right)$ parameters is presented. The uncertainty expectations for these parameters plus the $\left(\omega_{s}, \gamma, a, b, e, d\right)$ parameters are calculated.

Traceability to the National Institute of Standards and Technology is defined and the method of achieving traceability is described. The role of accreditation through the National Voluntary Laboratory Accreditation Program or the Measurement Assurance Program is discussed.
\end{abstract}

\title{
KEY WORDS
}

Reflectance

Retroreflectometer

Retroreflective

Calibration facility

Alignment

Uncertainty 


\section{TABLE OF CONTENTS}

\section{PREFACE}

ABSTRACT

LIST OF FIGURES

\section{Introduction and Overview}

1.1 Problem Statement and Research Approach

1.2 Summary of Instrument Requirements

1.3 Instrument Overview

2. Source Characteristics

2.1 Strip Lamp Projection System

2.21000 W FEL Projection System 10

2.3 Sphere Projection System

3. Goniometer Characteristics

3.1 Three Axes of Rotation

3.2 Three Axes of Translation and Rail System

3.3 Sample Holder Plate

3.4 General Construction Requirements

4. Detector Characteristics

4.1 Three Axes Detector Stages

4.2 Photometric Detection

4.3 Spectroradiometric Detection

\section{Alignment}

5.1 Absolute Observation Angle Alignment 19

5.2 Absolute Entrance Angle Components Alignment 20

5.3 Absolute Rotation Angle Alignment 20

6. Expected Uncertainties

6.1 Absolute Uncertainty in $\alpha \quad 22$

6.2 Absolute Uncertainty in $\beta_{1}, \beta_{2}$ and $\beta \quad 26$

6.3 Absolute Uncertainty in $\varepsilon \quad 28$

6.4 Absolute Uncertainty in Calculated Angles 30

7. Traceability to NIST 36

7.1 Statement of Policy 36

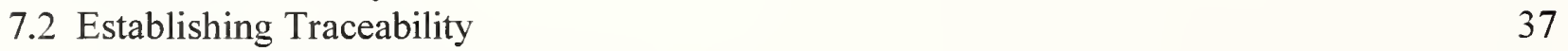

7.3 Measurement Assurance Program 37 
$\begin{array}{ll}\text { ACKNOWLEDGMENTS } & 40\end{array}$

$\begin{array}{ll}\text { APPENDIX A Bibliography of Retroreflection Standards A-1 } & \text { A }\end{array}$

$\begin{array}{lc}\text { APPENDIX B Source Flux and Throughput Calculations } & \text { B-1 }\end{array}$

REFERENCES 


\section{LIST OF FIGURES}

Figure 1 - The Relationship of the Three Angular Systems

Figure 2 - The Road Marking System of Angles

Figure 3 - Solid Model of Source and Observation Angle Positioner

Figure 4 - Cross Section of Tunnel

Figure 5 - Top View of Tunnel and Components

Figure 6 -Strip Lamp Projection System

Figure 7 - Strip Lamp Uniformity Plot

Figure 8 - FEL Uniformity Plot

Figure 9 - Sphere Source Uniformity Plot

Figure 10 - Six - Axis Goniometer

Figure 11 - Horizontal and Illumination Linear Axis

Figure 12 - Aperture Holders with Different Apertures

Figure 13 - Alignment of Rotation Angle

Figure 14 - Movements Along the Observation Angle Positioner

Figure 15 - Orientation Angle Uncertainty Dependence

Figure 16 - Presentation Angle Uncertainty Dependence 


\section{LIST OF TABLES}

Table 1 - Expected Uncertainty Factors

Table 2 - Uncertainty Budget for Setting the Initial Observation Angle Absolutely

Table 3 - Uncertainty Budget for Setting the Aperture Separation, $c$

Table 4 - Uncertainty Budget for Observation Distance, $d$

Table 5 - Uncertainty Budget for Arbitrary Setting of the Observation Angle

Table 6 - Uncertainty Budget for Setting Entrance Angle Components, $\beta_{1}$ and $\beta_{2}$

Table 7 - Uncertainty Budget for Setting Arbitrary Entrance Angle Components, $\beta_{1}$ and $\beta_{2}$

Table 8 - Uncertainty Budget for Setting Arbitrary Entrance Angle, $\beta$

Table 9 - Uncertainty Budget for Determining the Observation Half-Plane

Table 10 - Uncertainty Budget for Aligning the Straight Edge

Table 11 - Uncertainty Budget for Rotation Angle, $\varepsilon$

Table 12 - Uncertainty Budget for Orientation Angle, $\omega_{\mathrm{s}}$

Table 13 - Uncertainty Budget for Presentation Angle, $\gamma$

Table 14 - Uncertainty Budget for Observation-elevation Angle, $a$

Table 15 - Uncertainty Budget for RM First Azimuthal Angle, $b$

Table 16 - Uncertainty Budget for Illumination Elevation Angle, $e$

Table 17 - Uncertainty Budget for RM Second Azimuthal Angle, $d$ 


\section{INTRODUCTION AND OVERVIEW}

Presented in this report are the details required to construct the National Calibration Facility for Retroreflective Traffic Control Materials. Section 1 contains the problem statement along with the research approach for solving this problem. The requirements for the reference retroreflectometer, based on an examination of national and international standards and discussion with experts in the field of retroreflective measurements, are presented. Section 1 concludes with a general overview of the reference retroreflectometer plans.

Sections 2, 3 and 4 discuss the proposed plan and expected results for the source, the goniometer and the detectors. Section 5 gives an in-depth description of how the reference retroreflectometer will be aligned and absolutely calibrated for $\left(\alpha, \beta_{1}, \beta_{2}, \varepsilon\right)$ parameters. Section 6 provides the uncertainty expectations for these parameters plus the $\left(\omega_{\mathrm{s}}, \gamma, a, b, e, d\right)$ parameters that are important in other representations: Intrinsic, Application and Road Marking.

Section 7 defines traceability to NIST and its achievement is described. The role of accreditation through the National Voluntary Laboratory Accreditation Program (NVLAP) or the Measurement Assurance Program (MAP) is discussed.

\subsection{PROBLEM STATEMENT AND RESEARCH APPROACH}

Retroreflective traffic control devices are widely used for nighttime visibility and safety. Congress has directed the U.S. Department of Transportation to establish "a standard for a minimum level of retroreflectivity that must be maintained for pavement markings and signs which apply to all roads open to public travel." Establishing a national standard for minimum levels of retroreflectivity will require accurate methods to measure retroreflectivity. Instruments are commercially available for measuring the retroreflectivity of signs and markings, and documented standards establish procedures for such measurements. However, there can be significant variability among instruments measuring the same object, and the standards documents do not ensure accuracy of the instruments. There are currently no traceable methods in the United States to determine the accuracy of measurements, because national calibration standards for retroreflectivity do not exist. The primary mission of the National Institute of Standards and Technology (NIST) is to provide such national calibration standards in a variety of areas important to government or industry. Within NIST, the Optical Technology Division maintains standards and provides calibrations for measurements involving optical radiation.

The measurement of retroreflectivity is essentially a measurement of the reflectance of materials under specified geometrical and spectral conditions. It therefore involves the areas of photometry and spectrophotometry within the Optical Technology Division. While the distinction between these two areas can overlap, in general NIST photometry personnel maintain the national scales for luminous intensity, illuminance and luminance, while spectrophotometry personnel maintain the national scales for spectral reflectance and transmittance.

NIST was previously involved in retroreflectivity with a reference instrument and a Measurement Assurance Program. However, retirement of essential personnel and lack of modernization of the reference instrument, particularly automation, ended this program. The specialized room used by the reference instrument and some of the components are still available for the new reference instrument. A workshop held in 1997 stressed the need for NIST to again become involved in retroreflectivity, and in response, NIST personnel began to participate in national and international organizations dealing with retroreflectivity, namely ASTM International (American Society of Testing and Materials) and the International Commission on Illumination (CIE). The present project is a direct consequence of this involvement. 
The objective of this project is two-fold. First, to develop a dedicated reference instrument for measuring retroreflective materials, and second, to develop a calibration program that provides traceability to the relevant national scales maintained by NIST. The expertise of the personnel in the specific area of retroreflectivity and in the broader areas of photometry and spectrophotometry, the existing facilities, and the mission of NIST, will all assure that the objective is attained.

The research detailed in this proposal is directed toward developing a reference instrument that will provide the basis for a national calibration facility for retroreflectivity. This research is conveniently divided into two phases. Phase I consists of those tasks necessary to design the reference instrument. Phase II involves the construction and characterization of the instrument. The specific tasks in Phase I are as follows:

Task 1. Literature review. This review will include all of the existing national and international calibration and measurement methods of, and specifications for, retroreflective traffic control materials, with particular attention to the material, geometric, and spectral requirement capabilities. The review will also include visits to facilities such as the $3 \mathrm{M}$ Company in Minnesota and the Turner Fairbanks Highway Research Center in Virginia to assess current retroreflectivity measurements. Facilities at the British Standards Institute (BSI) in England and the Federal Institute for Materials Research and Testing (BAM) in Germany will be visited.

Task 1 has been completed and the list of documentary standards is presented in Appendix A.

Task 2. Requirements. These requirements consist of the parameters necessary to calibrate retroreflective traffic control materials and are based in part on the literature review conducted in Task 1. These parameters include materials and sizes of retroreflecting devices, geometry of the entrance and observation angles, apertures, and spectral conditions. Also included in this task will be the requirements necessary to measure and characterize fluorescent materials. A bi-spectral measurement, necessary for complete characterization of fluorescent material, is not included in this research plan.

Task 2 has been completed and presented in Sec. 1 Summary of Instrument Requirements.

Task 3. Preliminary design. A preliminary design for the reference instrument will be produced, based upon the requirements identified in Task 2. This design will include all of the components necessary for the source, goniometer, detector, and data acquisition and control systems, as well as a plan for characterizing the operation of the instrument to ensure that it meets the requirements.

Task 3 has been completed and presented in Secs. 2 through 6 of this report. Also, the preliminary design was presented at the Annual Meeting of the Council for Optical Radiation Measurements (CORM), meeting on May $6^{\text {th }}-8^{\text {th }}, 2002$ specifically at the Optical Properties Group 4 (OP4) session on Retroreflection. The design was also presented at the $16^{\text {th }}$ Biennial Symposium on Visibility and Simulation hosted by the Transportation Research Board and the University of Iowa on June $2^{\text {nd }}-4^{\text {th }}, 2002$. 
Task 4. Uncertainty analysis. Based upon the design in Task 3, the uncertainties in the measurement of typical retroreflective traffic control materials will be estimated. These estimates may require iterations between this Task and Task 3.

Task 4 is completed for all of the geometrical parameters that define the position of the retroreflective device and is presented in Sec. 6 of this report. The final uncertainty budget for the measurement of the coefficient of retroreflection or the coefficient of line retroreflection will require experimental measurements once the instrument is complete. A simulation program is currently under development to provide preliminary results.

Task 5. Traceability to NIST. Possible mechanisms for providing traceability of calibrated standards to NIST will be investigated. There is not now, nor will there be, the resources for calibrating many samples in a rapid, inexpensive manner. Therefore, one or several mechanisms need to be developed to provide traceability to NIST that is agreeable both to NIST and to the customers. Possible mechanisms include accreditation of secondary laboratories through the NVLAP, measurement assurance program sets, and guidelines for customer standards submitted for the calibration service. The possibility of generating standard reference materials will be assessed. The assessment will involve discussions within NIST on which mechanisms are viable and with potential secondary laboratories on their reactions to these mechanisms.

Task 5 is complete and presented in Sec. 7 of this report.

Task 6. Interim report. An interim report will be prepared documenting Tasks 1 to 5 , including a detailed work plan for Phase II. This report will follow the guidelines set forth by the NCHRP. The present document satisfies this requirement.

Task 7. Meet with the project panel. This meeting will occur approximately one month after submission of the interim report in Task 6.

The construction and validation of the reference instrument will occur in Phase II. In general terms, the goals for the instrument can be divided into two categories. First, the instrument will satisfy all the current requirements detailed in relevant documentary standards for materials, geometric, and spectral conditions. Second, the instrument will be able to accommodate additional geometric and spectral capabilities to increase its utility. The specific tasks in Phase II are as follows:

Task 8. Final design. A final design of the instrument will be prepared based upon the results from Phase I.

Task 9. Construct instrument. The components will be acquired and assembled to produce a reference instrument for measuring the retroreflectivity of traffic control materials based upon the design in Task 8.

Task 10. Validate instrument. Fully characterize the performance of the instrument to ensure that it meets the requirements and uncertainties identified in Tasks 2 and 4. This characterization 
may involve informal collaborations with other laboratories to determine agreement of results from common samples.

Task 11. Demonstrate. Conduct a demonstration of the capabilities and operation of the instrument for the Project Panel.

Task 12. Calibration program. Finalize the details of the calibration service described in Task 5.

Task 13. Final report. Prepare a final report that documents the entire research effort in Tasks 1 through 12 , in conformance with guidelines set forth by the NCHRP.

\subsection{SUMMARY OF INSTRUMENT REQUIREMENTS}

No single document specifies the necessary requirements for a reference retroreflectometer. Appendix $\mathrm{A}$ is a list of collected national and international retroreflection documentary standards. The requirements presented here are based on these retroreflection standards, related support standards, and interviews with knowledgeable sources.

To completely specify the geometric relations between the source, the retroreflector and the detector, four angles are required. Four systems are currently used and accepted. The first system is the CIE Goniometer System where the illumination axis is the principal direction. The observation and orientation of the retroreflector are expressed in relation to the illumination direction. Figure 1 shows the four angles in the CIE Goniometer System, the observation angle, $\alpha$, the two components of the entrance angle, $\beta_{1}$ and $\beta_{2}$, and the rotation angle, $\varepsilon$. Two other popular conventions for retroreflective sheeting material is the Intrinsic System composed of the observation angle, $\alpha$, the entrance angle, $\beta$, the presentation angle, $\gamma$, and the orientation angle $\omega_{\mathrm{s}}$, and the Application System composed of the observation angle, $\alpha$, the entrance angle, $\beta$, the rotation angle, $\varepsilon$, and the orientation angle, $\omega_{5}$. The Intrinsic System is more closely related to the inherent optical properties of the material. The Application System uses the Datum Axis, defined as a designated axis of a retroreflector from the retroreflector point of reference with a direction perpendicular to the retroreflector axis, as the fundamental direction and relates the other angles to its position, which is representative of how retroreflective sheeting is presented on the roadway. The fourth system is the Road Marking System (RM), shown in Figure 2. The Road Marking System is useful for horizontal coatings and is composed of the observation-elevation angle, $a$, the illumination-elevation angle, $e$, the RM first azimuthal angle, $b$, and the second azimuthal angle, $d$.

The source of the reference retroreflectometer should be a projector capable of uniformly overfilling the specimen. The uniformity of illuminance should be within $\pm 5 \%$ of the mean value measured normal to the source. For most applications, the relative spectral power distribution of the source should be equal to CIE standard illuminant $\mathrm{A}(2856 \mathrm{~K})$ with an uncertainty of $\pm 20 \mathrm{~K}$. (All uncertainties in this report are of coverage factor $k=2$, unless otherwise stated.) The source should also be capable of providing other important relative spectral power distributions. The source illuminance should not vary by more than $1 \%$ over the time of the measurement and should emit unpolarized light. Included in the design of the source is the source aperture. The recommended aperture sizes are $3,6,10$, and 20 arc minutes for signage and $20 \times 10$ arc minutes for road marking materials. The illumination of the source aperture must be sufficiently uniform so as not to add positional uncertainty to the centroid of the aperture. 


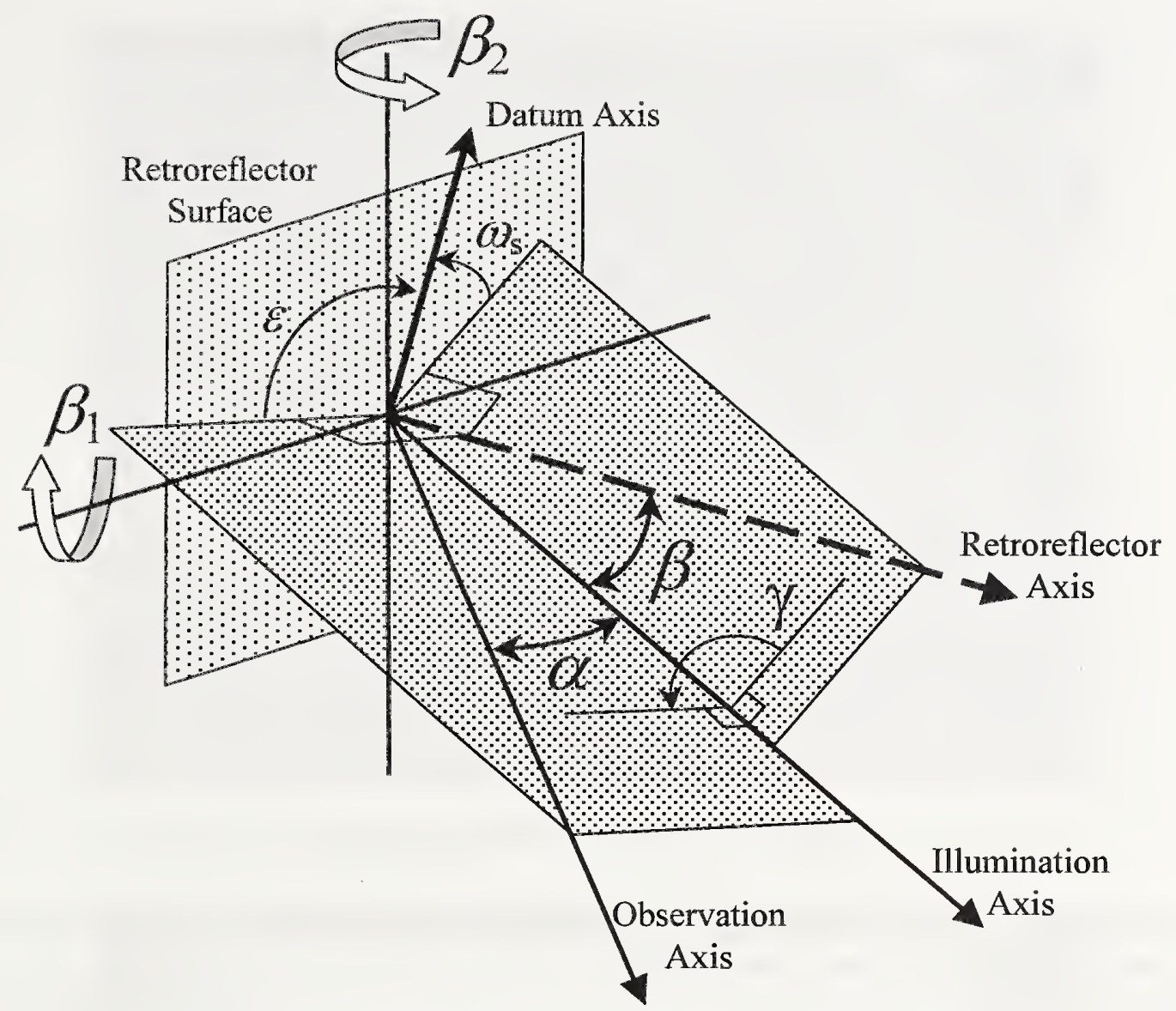

Figure 1 - The relationship of the three angular systems.

The goniometer of the reference retroreflectometer should be capable of movement in three axes, entrance angle component $\beta_{1}$, entrance angle component $\beta_{2}$ and rotation angle, $\varepsilon$. The uncertainty in setting $\beta_{1}$ and $\beta_{2}$ should be less than $0.1^{\circ}$ and the resolution should be better than $0.02^{\circ}$. The uncertainty in setting $\varepsilon$ should be less than $0.2^{\circ}$ and the resolution should be better than $0.04^{\circ}$. The goniometer should be able to accommodate sign specimens 0.3 meters square and pavement markings panels $10 \mathrm{~cm}$ to $15 \mathrm{~cm}$ wide and $60 \mathrm{~cm}$ to $120 \mathrm{~cm}$ long. The goniometer has to be able to position the detection system in place of the retroreflector specimen easily. Also associated with the goniometer is the illumination distance, which is the distance between the center of the goniometer and the source aperture. The illumination distance needs to be variable from 7.5 $\mathrm{m}$ to $30 \mathrm{~m}$ and should have an uncertainty of less than $0.01 \mathrm{~m}$.

The detection system is composed of the observation angle positioner and photometer head. The observation angle positioner is designed to support and separate the photometer head from the light source. The observation distance should be maintained equal to the illumination distance with an uncertainty of less than $0.01 \mathrm{~m}$. The observation angle, $\alpha$, should be set with an uncertainty of less than $0.002^{\circ}$. The recommended aperture sizes for the photometer head aperture are $3,6,10$, and 20 arc minutes. The responsivity and dynamic range of the photometer head should be sufficient that readings of the light source and the test retroreflector have a resolution of a least 1 part in 50 . The linearity of the detection system over the range of the measurement should be within $1 \%$. 


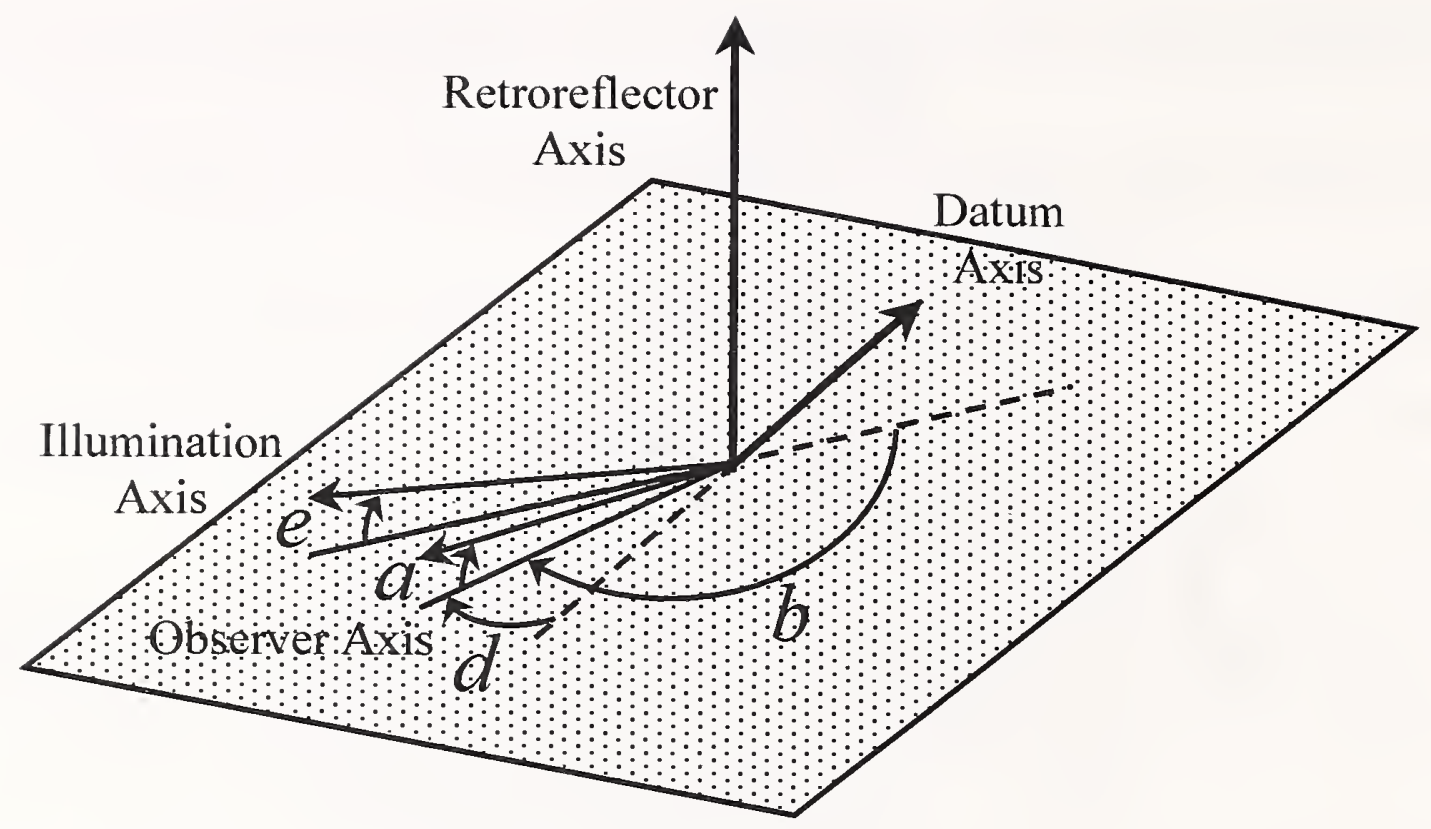

Figure 2 - The Road Marking System of angles.

Correction factors may be used to correct non-linearities. The relative spectral responsivity of the photometer head should match the CIE $V(\lambda)$-function with an $f_{1}$ ' tolerance better than $3 \%$. Spectral mismatch corrections may be applied to the $V(\lambda)$-function. The readings of the photometer head from a constant source should not vary more than $1 \%$. The specifications for nighttime color measurements or retroreflected color are not well specified. The spectroradiometer requirements are that it has a very good linear response and its wavelength scale must be calibrated.

\subsection{INSTRUMENT OVERVIEW}

The expected requirements for the NIST reference retroreflectometer are briefly described in this section and in more detail in the following chapters. Figures 3 and 4 show the general layout of the retroreflectance facility. Figure 5 is a top-view block drawing showing the position of the devices in the tunnel. The source and detection system are on a $1.52 \mathrm{~m}$ by $3.65 \mathrm{~m}$ optic table and the goniometer is on a rail system. The source is enclosed in a light tight box to reduce stray light. Also to reduce stray light, baffles swing out away from the wall at various distances depending on the location of the goniometer.

The source is composed of a $5 \mathrm{~cm}$ diameter sphere coated with a highly reflective diffuse material pumped by a $1000 \mathrm{~W}$ FEL in an ellipsoidal reflector. The $1000 \mathrm{~W}$ FEL is operated with a stability of better than $0.035 \%$. The projection system is an Abbe projector. The correlated color temperature produced by the system will be $2856 \mathrm{~K} \pm 10 \mathrm{~K}$. The uniformity will be within $\pm 1 \%$ of the mean value obtained normal to the source at the goniometer and at the plane of the source aperture. The integrating sphere system has the flexibility of being optically pumped by alternate sources such as high-intensity discharge (HID) lamps, xenon arc lamps, or even monochromatic sources such as a tunable laser. The source apertures will range from 3 arc minutes to 20 arc minutes and will be measured to an uncertainty of $0.000025 \%$. 


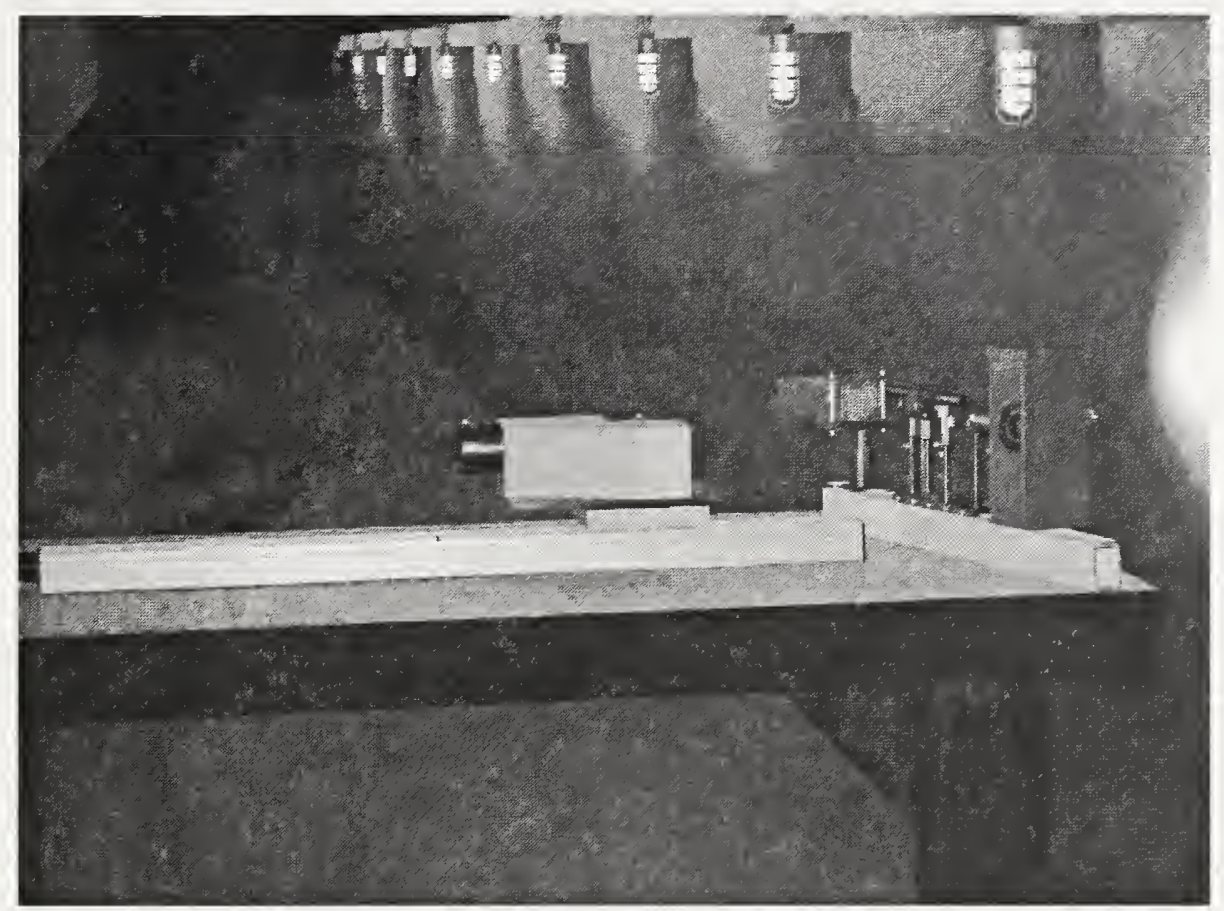

Figure 3 - Solid Model of Source and Observation Angle Positioner

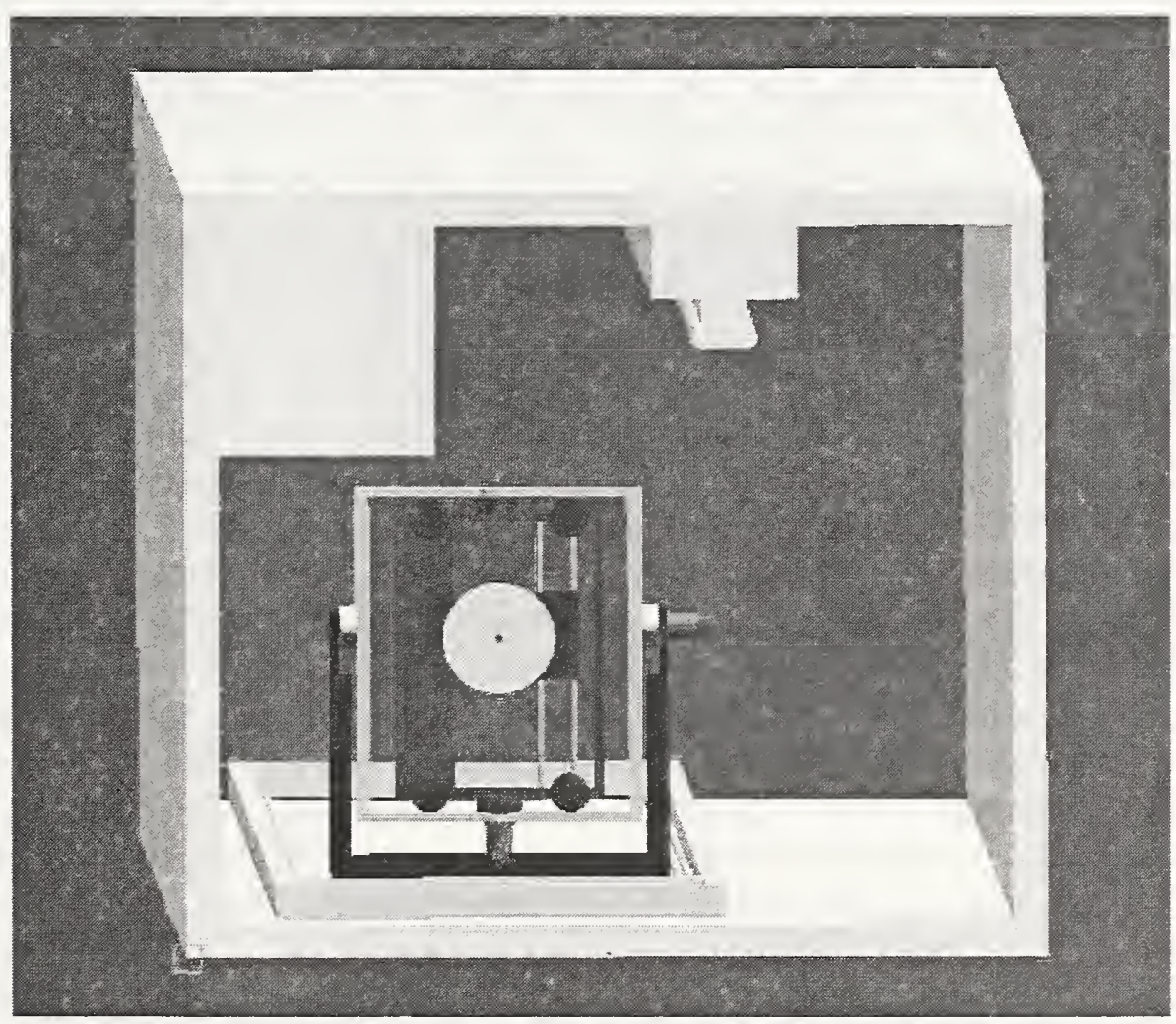

Figure 4 - Cross Section of Tunnel 

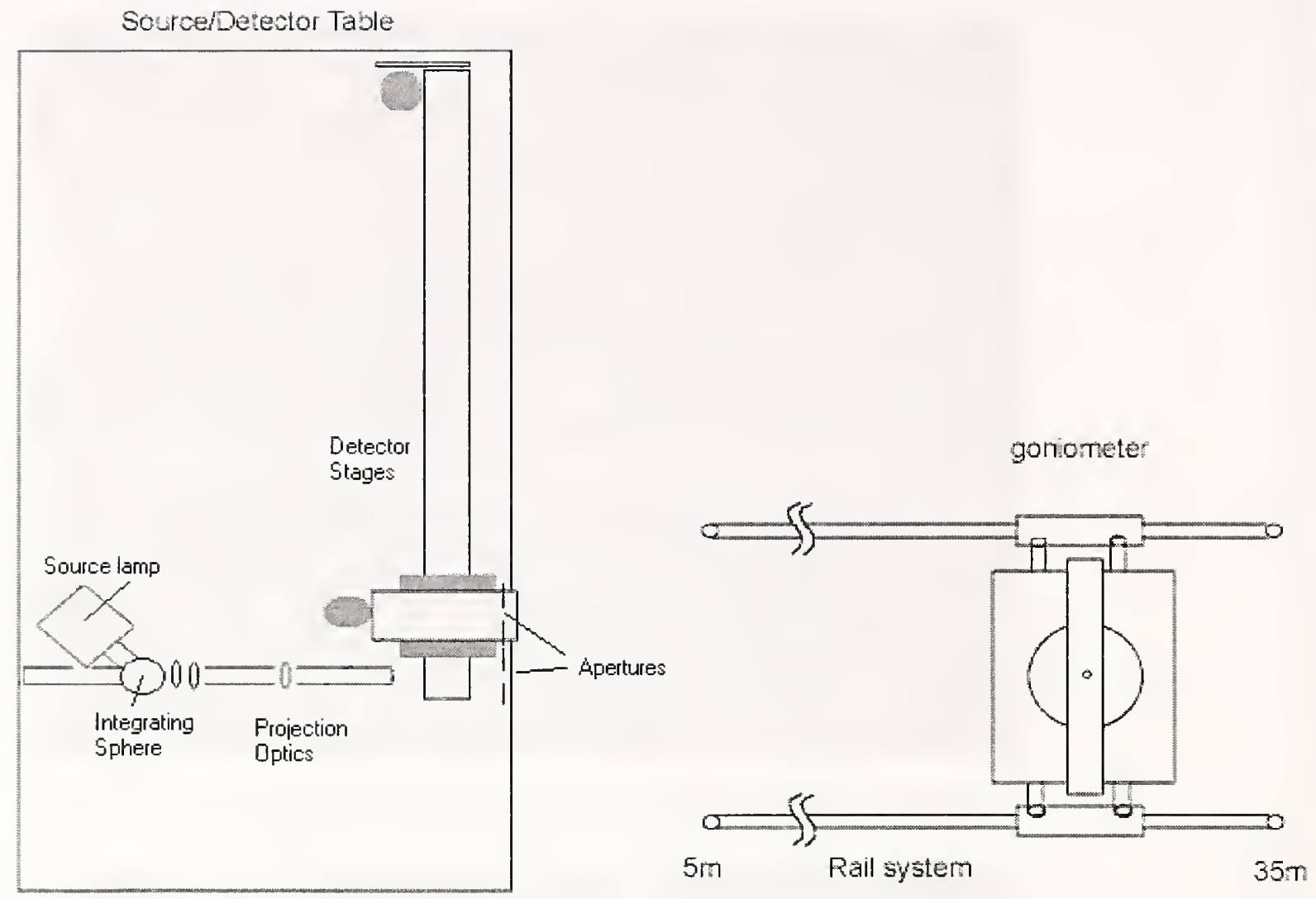

Figure 5 - Top View of Tunnel and Components

The goniometer of the reference retroreflectometer will be mounted on a rail system. The illumination distance will be variable from $5 \mathrm{~m}$ to $35 \mathrm{~m}$ and will have an absolute uncertainty of $0.001 \mathrm{~m}$ and an encoder resolution of $0.0003 \mathrm{~m}$. The $\beta_{1}$ and $\beta_{2}$ axes will have an absolute uncertainty of $0.009^{\circ}$ and an encoder resolution of $0.0005^{\circ}$. Both axes have a range of $\pm 95^{\circ}$. The rotation axis, $\varepsilon$, will have an uncertainty of $0.090^{\circ}$ and an encoder resolution of $0.0005^{\circ}$. The largest retroreflective device the goniometer can accommodate is a circular device $95 \mathrm{~cm}$ in diameter and will have a clear view to allow various lengths of pavement marking. The mounting bracket will use either a vacuum or alignment pins and clamps to hold the devices. The mounting bracket has an adjustable depth to accommodate samples of different thicknesses. The bracket can be replaced with one that holds the detector. In addition to the three automated rotation axes, the goniometer will be able to translate along three axes using stepping motors, providing a positional uncertainty of 0.1 $\mathrm{mm}$. These translations are primarily for research purposes such as studying uniformity of the source and the sample.

The detector is supported by the observation angle positioner, which is comprised of a $2 \mathrm{~m}$ translation stage, a rotation stage and a $0.2 \mathrm{~m}$ translation stage. Each of these motions has an optical encoder to ensure accuracy. The uncertainty of the entrance angle, $\alpha$, is $0.00057^{\circ}$. Translation of the $0.2 \mathrm{~m}$ stage allows the observation distance to be maintained equal to the illumination distance to a relative uncertainty of $0.0020 \mathrm{~m}$. The observer apertures will range from 3 arc minutes to 20 arc minutes with the areas measured to a relative uncertainty of $0.000025 \%$. The photometers developed and used at NIST typically have a responsivity of $3 \mathrm{nA} / \mathrm{lx}$ and an $\mathrm{f}_{1}{ }^{\prime}<2.5 \%$. Therefore, 
based on this detector and the source the detection limit (signal-to-noise of 1000:1) for the NIST reference retroreflectometer will be $0.41[\mathrm{mcd} / \mathrm{lx}] / \mathrm{m}^{2}$ for a sign $0.2 \mathrm{~m} \mathrm{x} 0.2 \mathrm{~m}$ and $0.07[\mathrm{mcd} / \mathrm{lx}] / \mathrm{m}$ for a pavement marking $10 \mathrm{~cm}$ wide $\mathrm{x} 120 \mathrm{~cm}$ long. The spectroradiometer for the NIST reference retroreflectometer has not been selected.

\section{SOURCE CHARACTERISTICS}

A significant amount of effort has been devoted to improving the source. Three types of projection systems have been investigated. The first system is a $100 \mathrm{~W}$ tungsten strip lamp using an Abbe projection system. The second system is a $1000 \mathrm{~W}$ FEL lamp using a Köhler illuminator. The final system is a $5 \mathrm{~cm}$ diameter sphere coated with a highly reflective diffuse material optically pumped by a $1000 \mathrm{~W}$ FEL. It uses an Abbe projection system to image the exit port.

The illuminance of all three systems is dependent on the current control of the lamps. The lamps are powered by a constant-current power supply that is analog controlled by the output of two 12-bit digital-to-analog controllers. One analog output is divided by 4096 and then added to the second analog output to achieve $100 \mu \mathrm{V}$ resolution. The digital-to-analog controller is programmed based on the voltage drop across a calibrated shunt resistor. Using this feedback loop the current will vary by less than $0.005 \%$. The illuminance of a tungsten lamp is approximately proportional to the current to the power of 7 . Therefore, the illuminance of the tungsten lamp in any of the three systems will vary by less than $0.035 \%$. The correlated color temperature will be determined by a spectrometer that is calibrated against the NIST photometric color temperature standards using a PTFE pressed plaque as the input optic. The PTFE plaque then can be placed in front of any of the projection systems to allow the current to be set such that the light has a $2856 \mathrm{~K} \pm 10 \mathrm{~K}$ distribution.

\subsection{STRIP LAMP PROJECTION SYSTEM}

The first system investigated is a $100 \mathrm{~W}$ tungsten strip lamp used in an Abbe projection system. This is the source that was used in the previous retroreflectance facility. Figure 6 shows a schematic of the projection system. An aspheric lens with a diameter of $60 \mathrm{~mm}$ and a focal length of $39 \mathrm{~mm}$ is the collection optic. This aspheric lens images the $2 \mathrm{~mm} \times 18 \mathrm{~mm}$ tungsten strip on a $5 \mathrm{~mm}$ aperture. The $5 \mathrm{~mm}$ aperture limits the transmitted light to an image produced from a $0.83 \mathrm{~mm}$ diameter circle on the tungsten strip. A variety of projection lenses are chosen to collimate the light and send it through the source aperture and down the range. The uniformity of this projection system is

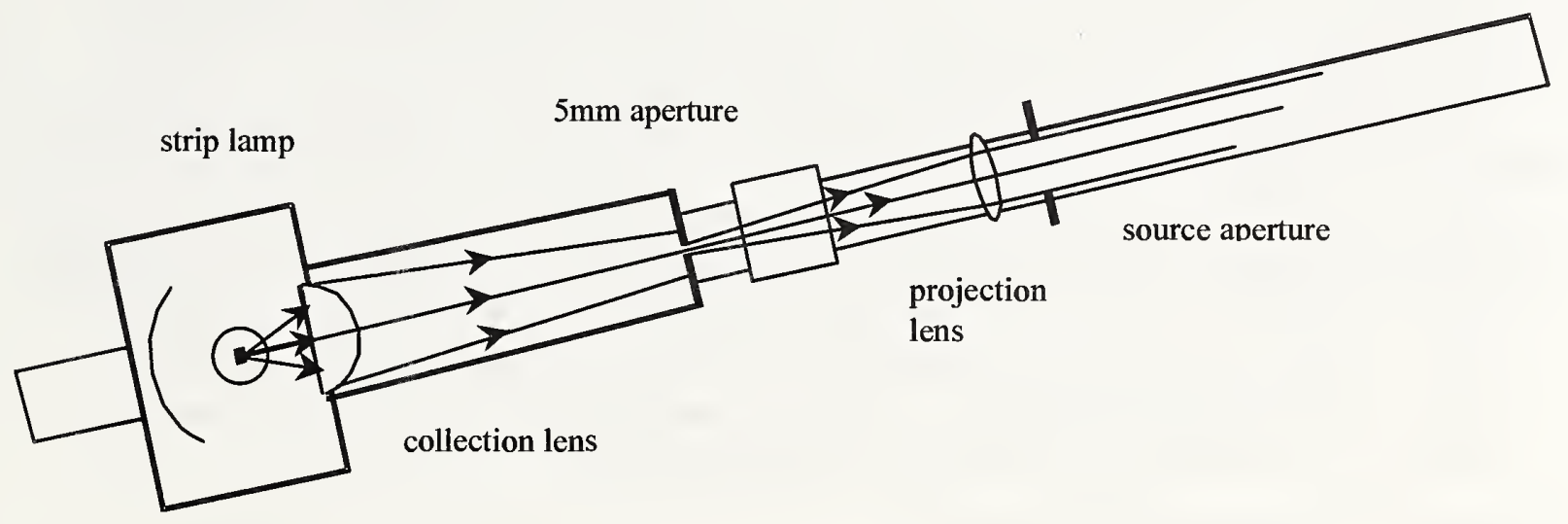

Figure 6 - Strip Lamp Projection System 


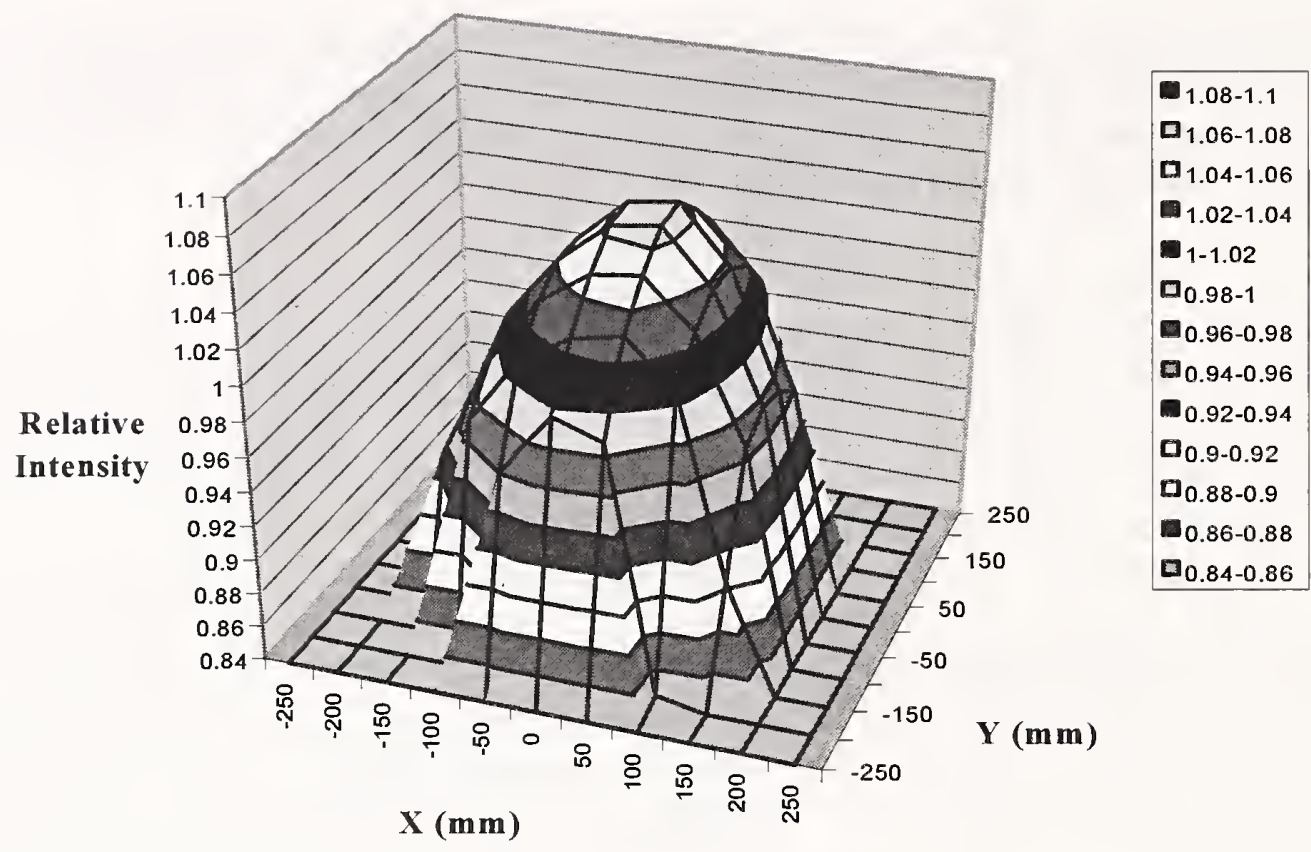

Figure 7 - Strip Lamp Uniformity Plot

expected to be good and the amount of light reaching the sample is calculated to be about $10 \mathrm{~lm}$. The radiance and throughput calculation is included in Appendix B.

The uniformity of this projection system was measured by scanning a photometer across the beam over a $50 \mathrm{~cm}$ range in both $\mathrm{x}$ and $\mathrm{y}$ perpendicular to the beam. Results shown in Figure 7 indicate the majority of the beam falls within $\pm 5 \%$ of the mean value of $7.3 \mathrm{~lm}$. In general the distribution of illuminance is very smooth, and could be improved to $\pm 3 \%$ with proper optical alignment. This system has acceptable uniformity but projects a modest amount of light.

\section{W FEL PROJECTION SYSTEM}

For the second system, a $1000 \mathrm{~W}$ FEL lamp was placed in the strip lamp housing, and the projection lens was moved to the focal plane formed by the condenser lens, as in a Köhler illuminator. In the first measurement, the reflected image of the filament was positioned to fill in the gaps between the individual filament turns. The resulting uniformity is quite poor, with significant areas exceeding $\pm 10 \%$ of the mean value. Then the back reflector was adjusted to place the reflected image beside the primary image, as in many commercial units. The uniformity was much improved, as shown in Figure 8. All of the luminous flux in the $35 \mathrm{~cm}$ beam diameter falls within $\pm 5 \%$ of the mean, and the edges are significantly brighter than with the strip lamp. As expected, the luminous flux is approximately 90 times that of the strip lamp, with a mean value of $620 \mathrm{~lm}$. The problem with this system is at the source aperture. An image of the filament along with its mirror image is visible to the eye. The non-uniformity of this system can cause large errors in the observation angle due to the alignment of the centroid of light with the source aperture.

\section{SPHERE PROJECTION SYSTEM}

The third system consists of a $5 \mathrm{~cm}$ diameter integrating sphere coated with Spectralon or PTFE with $1 \mathrm{~cm}$ diameter entrance and exit ports. The light from a $1000 \mathrm{~W}$ FEL lamp is coupled into the sphere 


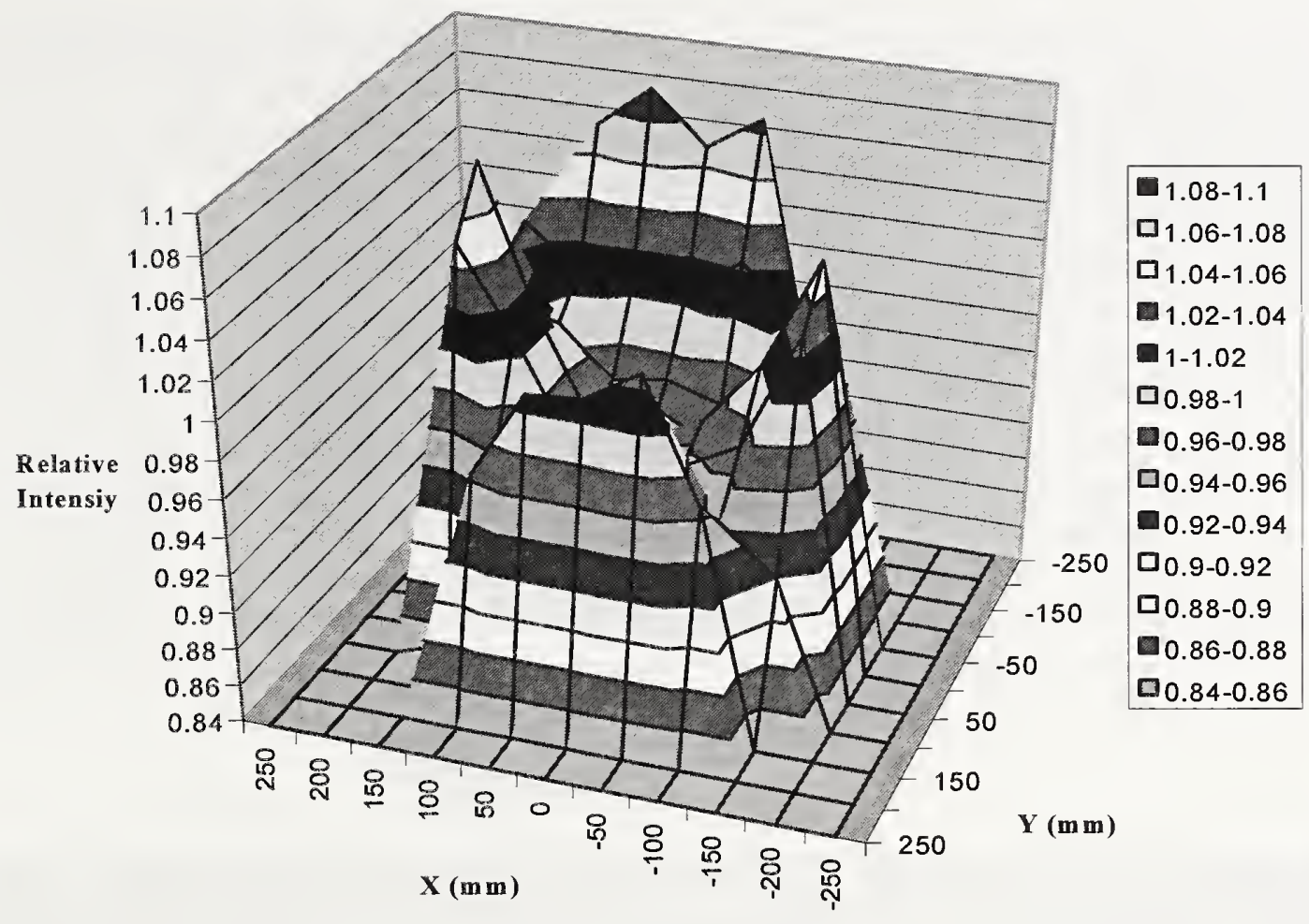

Figure 8 - FEL Uniformity Plot

using two elliptical mirrors. The exit port is imaged down range by an Abbe projection system consisting of two aspheric lenses and two plano-convex lenses. A preliminary experiment was performed to verify the expected uniformity of this system. A $10 \mathrm{~cm}$ diameter integrating sphere was illuminated with a $1000 \mathrm{~W}$ FEL placed next to the entrance aperture. The $12.5 \mathrm{~cm}$ diameter image was scanned for uniformity. The intensity distribution was easily the most uniform, with all of the useable area within $\pm 2 \%$ of the mean value of $7 \mathrm{~lm}$ (Figure 9). If an aperture is used to limit the size of the projected beam, it should be possible to achieve the desired $\pm 1 \%$ uniformity using a sphere source. The calculated luminous flux for the $5 \mathrm{~cm}$ sphere and the elliptical mirrors is nearly $1000 \mathrm{~lm}$, as shown in Appendix B.

The advantage of the sphere projection system is that almost any light source can be coupled into the sphere without changing the projection optics. For example, the new high intensity discharge (HID) lamps that are available in cars have a very distinct spectral pattern. The retroreflectance of devices can be calculated if spectral coefficients of retroreflection are measured, but to experimentally verify the results, the sphere projection system is the only option.

Additionally, for research purposes a portable tunable laser system can pump the sphere to create a monochromatic source to measure fluorescence bi-spectrally. 


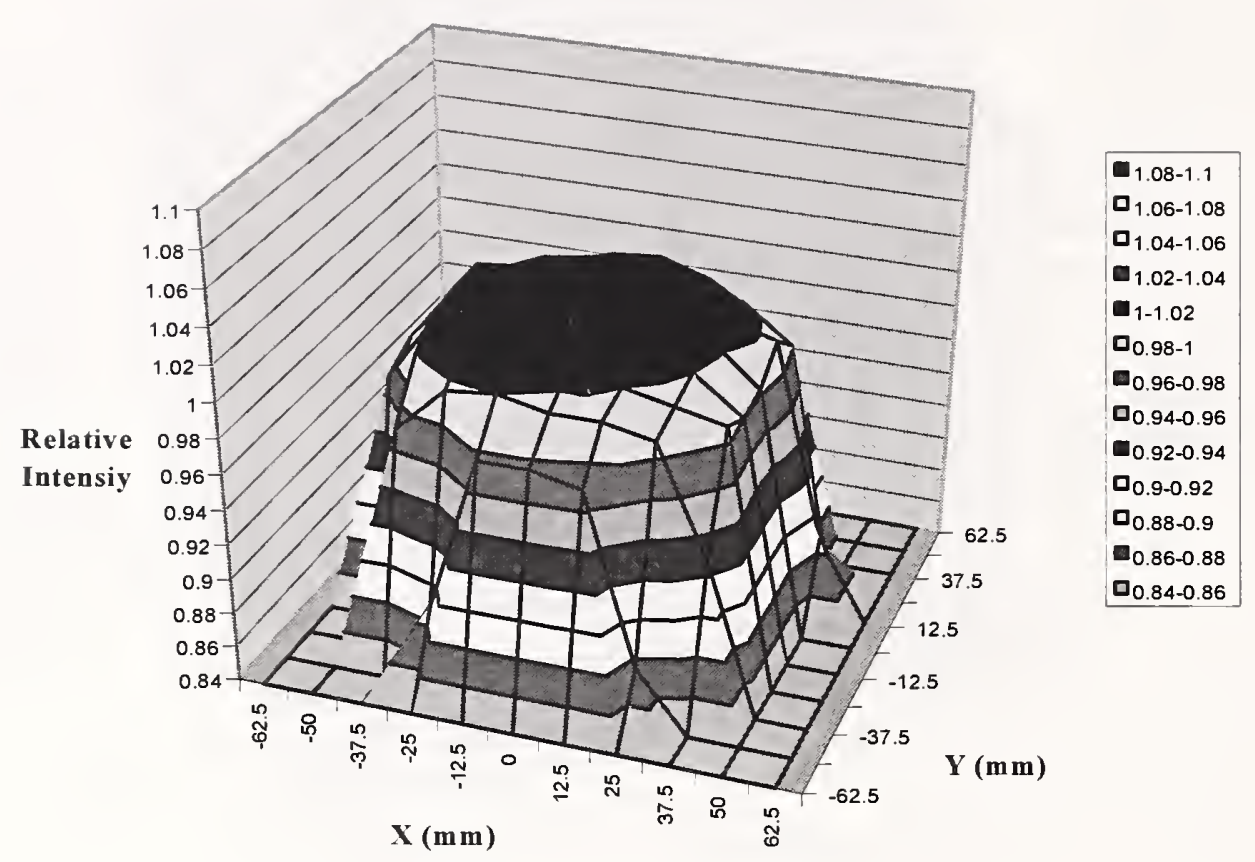

Figure 9 - Sphere Source Uniformity Plot 


\section{GONIOMETER CHARACTERISTICS}

The goniometer is a six-axis serial stacked positioning device. The source and detector lie in a horizontal plane. In its zeroed position the six-axis system would cause a mirrored surface to reflect the light exactly back to the source. The six axes are composed of three powered rotary axes, two powered linear axes, and one manual linear axis. A representative schematic is shown in Figure 10. Starting with the fixed base the axes are ordered as linear (horizontal), rotary (entrance angle component, $\beta_{2}$ ), rotary (entrance angle component, $\beta_{1}$ ), linear (vertical), and rotary (rotation angle, $\varepsilon$ ). The sixth axis is a short stroke manually adjustable linear axis that adjusts for thickness variations of the specimens to be tested. The various specimens to be examined for their retroreflective properties are attached to a sample holder plate by a vacuum mount system or bolted and clipped to a solid backing plate. The sample holder plate is driven by the rotation angle axis. The sample holder can be removed and a detector bracket put in its place to support the detection system. The six-axis goniometer will be located on a positioning stage that moves along the illumination axis. The stage along the illumination axis will slide on the rail system from $5 \mathrm{~m}$ to 35 $\mathrm{m}$ from the source aperture and can be clamped into position at the desired location.

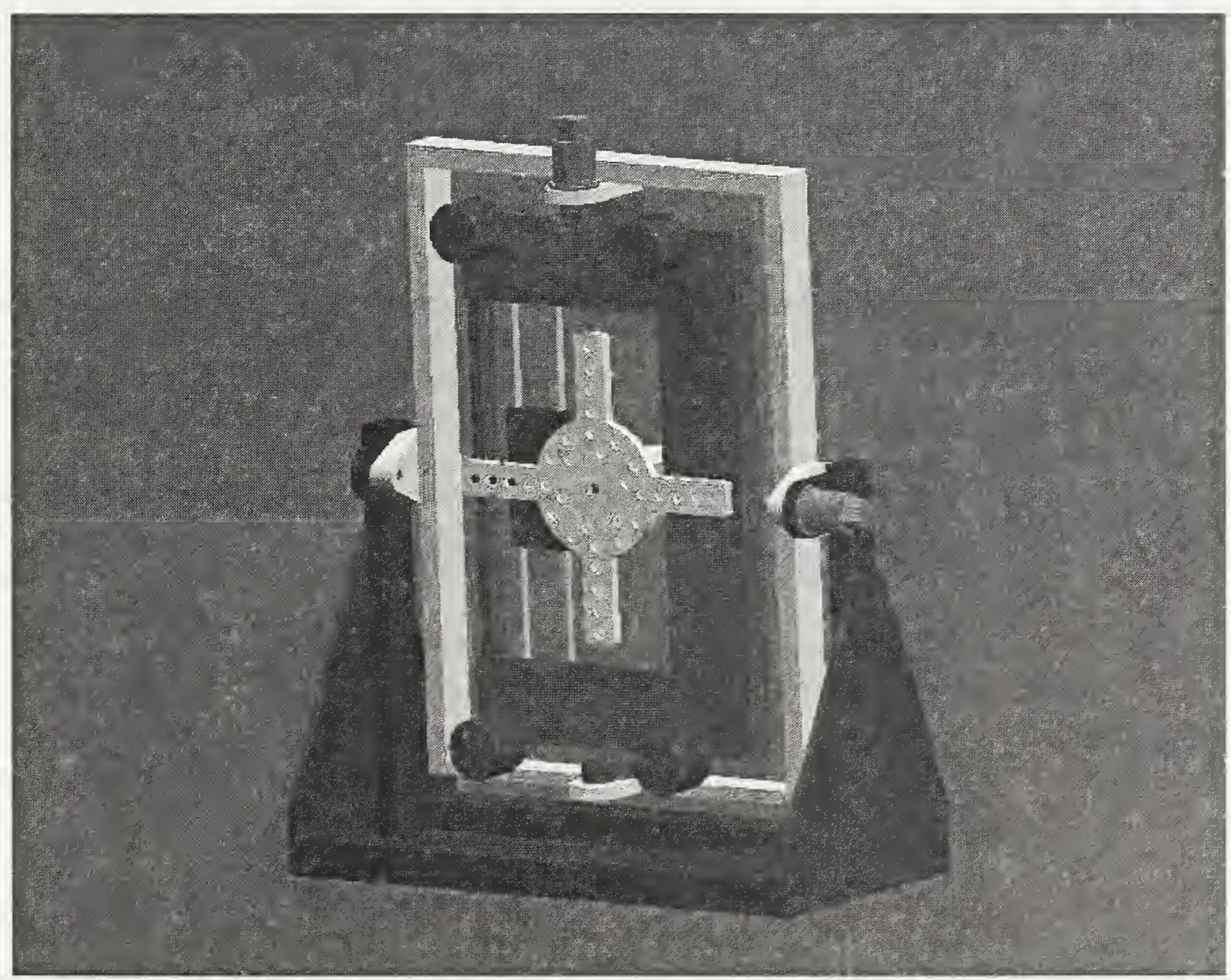

Figure 10 - Six - Axis Goniometer 


\subsection{THREE AXES OF ROTATION}

\subsubsection{Entrance Angle Component Axis, $\beta_{2}$}

The external fixed frame will have an attached motor and drive system to control the horizontal axis of rotation about the center of the frame. The $\beta_{2}$ axis is to have a range of $\pm 95^{\circ}$. It will have encoder feedback with resolution of $0.0005^{\circ}$ or better and an encoder scale accuracy of $0.005^{\circ}$ or better. The rotary encoder will be mounted to the driven frame after all sources of backlash have been removed. The drive system will have a step size of $0.001^{\circ}$ or better with a mechanical system positioning uncertainty of $0.01^{\circ}$ or less. The drive motor will be a Compumotor stepper motor and include a Compumotor indexer drive (model SX6). ${ }^{1}$ A harmonic drive type gear reducer will be used with a suitable output shaft and tapered-roller bearings. The pivot bearings opposite the drive should also be a tapered-roller bearing or a straight roller bearing. The $\beta_{2}$ axis will consist of a frame and sized to rotate just within the external fixed frame.

\subsubsection{Entrance Angle Component Axis, $\beta_{1}$}

To the $\beta_{2}$ frame a motor and gear reducer will be attached that will drive a vertical axis of rotation $\left(\beta_{1}\right)$. This axis will also be approximately centered in the $\beta_{2}$ axis frame, perpendicular to and intersecting in space with the $\beta_{2}$ axis. The $\beta_{1}$ axis will have a range of $\pm 95^{\circ}$. The $\beta_{1}$ axis will have an identical drive system as the $\beta_{2}$ axis. Its resolution and accuracy specifications will also be identical. The $\beta_{1}$ axis will have a rectangular frame that rotates just inside the $\beta_{2}$ axis frame. The frame for the $\beta_{1}$ axis will be designed in such a way that the frame, bearing mounts, counterweights, or any other object will not obscure the frontal view of the specimen through its entire $\pm 95^{\circ}$ of rotation (with the $\beta_{2}$ axis near zero). The $\beta_{1}$ axis will be counterweighted with fixed weights to ensure a balanced system.

\subsubsection{Rotation Angle Axis, $\varepsilon$}

Attached to the vertical axis is a rotation angle axis having $\pm 185^{\circ}$ of rotation. Its axis will be perpendicular to and intersect with the $\beta_{1}$ and $\beta_{2}$ axes when positioned at their zero location. The drive system will be identical to that used for the $\beta_{1}$ and $\beta_{2}$ axes. It will have the same encoder specifications and mounting requirements. However, its angular resolution will be $0.004^{\circ}$ or better and its angular system uncertainty will be $0.02^{\circ}$ or less.

The three powered axes described above will have over-travel limit switches followed by hard stops. The purpose of the fifth manual axis is to adjust a specimen so that its surface is coplanar with the $\beta_{1}$ and $\beta_{2}$ axes when located at their zero position, since any offset distance causes errors in the measurement. A means will be provided to indicate when the sample surface is coplanar. Its incremental division will be at least $0.0025 \mathrm{~cm}$. A means will be provided to lock this axis in place once the adjustment has been made. This manual short stroke thickness adjustment axis can be placed before the vertical linear axis, after it, or between the final rotation angle axis and the specimen holder plate depending on the design implementation.

\footnotetext{
${ }^{1}$ Certain commercial equipment, instruments, or materials are identified in this paper to foster understanding. Such identification does not imply recommendation or endorsement by the National Institute of Standards and Technology, nor does it imply that the materials or equipment identified are necessarily the best available for the purpose.
} 


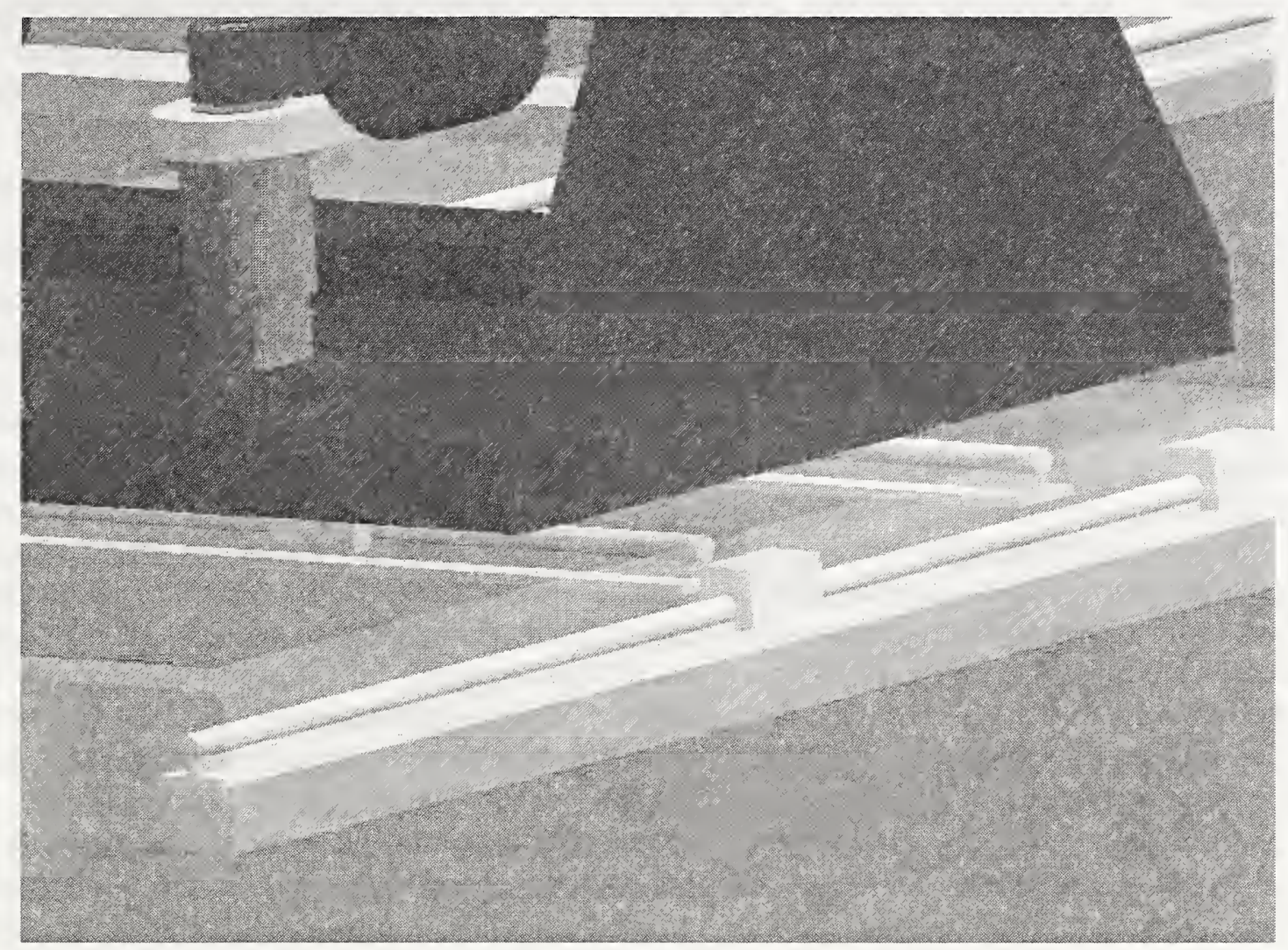

Figure 11 - Horizontal and Illumination Linear Axes

\subsection{THREE AXES OF TRANSLATION AND RAIL SYSTEM}

\subsubsection{Vertical Linear Axis}

A vertical linear axis will be connected to the $\beta_{1}$ axis frame. It will have $\pm 30 \mathrm{~cm}$ of travel. It will be driven by a Compumotor stepper motor and include a Compumotor indexer drive (model SX6). It will require an encoder. Its step size will be $0.0025 \mathrm{~cm}$. This axis will be counter-weighted so that an upward motion of the vertical axis is balanced by a counterweight moving in the opposite direction. The counterweight will be balanced within $10 \%$. The counterweight will not need to account for the sample mass.

\subsubsection{Horizontal Linear Axis}

A horizontal linear axis will support the goniometer. It will have $\pm 46 \mathrm{~cm}$ of travel. It will be driven by a Compumotor stepper motor and include a Compumotor indexer drive (model SX6). Its least step size will be $0.0025 \mathrm{~cm}$. A representative drawing is shown in Figure 11 along with the rail system that runs along the illumination axis.

\subsubsection{Illumination Linear Axis and Rail System}

The rail system supports the horizontal linear axis and the goniometer. It extends from 5 to $35 \mathrm{~m}$ and is operated manually. The goniometer and rail system will have a magnetic tape encoder that has a resolution of $10 \mu \mathrm{m}$ and an accuracy of $0.3 \mathrm{~mm}$. Once the goniometer is manually put in a 
position it locks into that position. Additionally, a linear axis is mounted to the clamping blocks, allowing the goniometer to automatically translate along the illumination axis. It will have $\pm 46 \mathrm{~cm}$ of travel. Its least step size will be $0.010 \mathrm{~cm}$. These translations are for research purposes such as studying uniformity of the source and the sample.

\subsection{SAMPLE HOLDER PLATE}

The sample holder plate will be attached to the rotation angle axis or the thickness adjustment axis. It will be sized to accept a sample that is at least $95 \mathrm{~cm}$ in diameter. The goniometer must also be able to accommodate road pavement marking samples, which may be as long as $120 \mathrm{~cm}$ and up to $20 \mathrm{~cm}$ wide. The $\beta_{1}, \beta_{2}$, and external frames must be sized accordingly.

A vacuum mount system is being considered to hold the samples in place, as described below. It will consist of between 10 and 50 vacuum cups arranged to hold various shaped signs and road marking material. The vacuum system will pull the specimen against a solid surface so that the sample is positively registered to a fixed depth. The vacuum cups should be sized to hold about 10 $\mathrm{kg}$. This represents a safety factor over the expected maximum target weight of about two. The vacuum system will be designed so that individual or sets of vacuum cups can be selected or deselected quickly by the machine operator. Unused vacuum cups should not get in the way of the specimen such as is the case when the specimen only covers a portion of a particular vacuum cup. The vacuum source should be routed to the sample holder plate in such a way as to allow free movement of the full range on all the other axes.

The detector system needs to be placed at the center of the goniometer for certain setup or calibrations procedures. The depth dimension must be behind the plane defined by the $\beta_{1}$ and $\beta_{2}$ axes. Therefore, the rotation angle axis and sample holder (and potentially the thickness adjustment axis depending on the design) must be removable. It should have tooling pins and bushings for relatively rapid removal and re-installation.

\subsection{GENERAL CONSTRUCTION REQUIREMENTS}

All frames and brackets should be made of aluminum to keep the weight to a minimum. Welded tubular aluminum frames are preferred over bolted assemblies since they are generally more rigid. The cross-section's dimensions and other bracing should be designed to provide frame stiffness that is consistent with the resolution and accuracy specified for each axis. In other words, the design should be optimally stiff and light. Being a serially stacked stage design, axes offsets are acceptable. However, all offsets and cantilevers should be kept to a minimum for best optimal stiffness. Steel should be used for any keyed shaft connections and steel thread inserts should be used on aluminum parts where frequent disassembly and re-assembly is expected. Stainless steels or other corrosion resistant materials should be selected. Exposed surfaces will be painted flat black. The lining will not generate particles through normal operation. All cables and vacuum lines will be cleanly routed and bundled with appropriate strain relief for the full range of motion. Lifting hooks at the top of the frame and forklift locations at the base from both approach directions will be provided. 


\section{DETECTOR CHARACTERISTICS}

\subsection{THREE AXES DETECTOR STAGES}

The detector stages or observation angle positioner consist of three stages, a $2 \mathrm{~m}$ stage, a rotation stage and a $20 \mathrm{~cm}$ stage. The long stage will have a step size of $0.2 \mu \mathrm{m}$ and an optical encoder allowing a positional uncertainty of $\pm 3 \mu \mathrm{m}$. It will be mounted on the optical table perpendicular to the illumination axis. The rotation stage will have a step size of $0.00008^{\circ}$ and an optical encoder allowing an angular uncertainty of $\pm 0.010^{\circ}$. The rotation stage will be centered and mounted on the long stage. The small stage will have a step size of $0.2 \mu \mathrm{m}$ and optical encoder allowing a positional uncertainty of $\pm 10 \mu \mathrm{m}$. The small stage will be mounted on top of the rotation stage. The small stage will have a mounting plate that will act as a kinematic mount. Various plates with aperture holders, optics and detectors will mount to this plate and a similar plate that can be attached to the goniometer. The positioning of these stages will allow the aperture holders to be positioned in front of and behind the source aperture holder, to allow accurate alignment, which is discussed in Sec. 5, ALIGNMENT. These three stages will set the observation angle and with these positioning uncertainties, the absolute uncertainty in the observation angle will be $0.00057^{\circ}$.

\subsection{PHOTOMETRIC DETECTION}

The photometric detection system consists of the observer aperture holder, a focusing optic, and the photometer head mounted on a plate that mounts kinematically to the observation angle positioner. The entire system will be enclosed in a light tight box to reduce stray light. This plate with its attached parts can also be mounted on the goniometer to measure the incident light on the retroreflective device. The goniometer will also be able to scan this photometric detection system across the projected source beam to assess uniformity.

The photometric detector consists of a silicon photodiode, a $V(\lambda)$-correction filter, and a thermoelectric temperature controller.[1] A high sensitivity, wide dynamic range current-to-voltage converter is mounted directly behind the photodiode to minimize noise.[2] The circuit has a switchable gain setting from $10^{4} \mathrm{~V} / \mathrm{A}$ to $10^{10} \mathrm{~V} / \mathrm{A}$. The linearity of the system will be tested on the NIST beam conjoiner instrument.[3] The system should be linear to $0.02 \%$ without correction factors. An input equivalent noise of $\approx 1 \mathrm{fA}$ is achieved at a gain setting of $10^{10} \mathrm{~V} / \mathrm{A}$ with an integration time of $1.67 \mathrm{~s}$, and a bandwidth of $0.3 \mathrm{~Hz}$. The spectral responsivity of the system, $s(\lambda)$, which includes the focusing optic, is measured at the Spectral Irradiance and Radiance Response Calibrations with a Uniform Source (SIRCUS) facility. The $f_{1}$ ' will be less than $2.5 \%$ for the photometric system. Since the spectral responsivity is measured absolutely, the illuminance responsivity, $R_{\mathrm{v}}[\mathrm{A} / \mathrm{lx}]$, of the photometric system is calculated for Planckian radiation at $2856 \mathrm{~K}$ (CIE Illuminant A). The magnitude of the illuminance responsivity will be about $3 \mathrm{nA} / \mathrm{lx}$. The uncertainty in the realization of the illuminance responsivity will be less than $0.40 \%(k=2)$. With the illuminance responsivity, the coefficient of retroreflection can be measured using the absolute method, in addition to the relative method cited in CIE 54.2 - 2001.

Since most of the retroreflective devices retroreflect a spectral distribution that is not CIE Illuminant $\mathrm{A}$, spectral mismatch correction factors will need to be calculated. The spectral mismatch correction factor is given by,

$$
c c f^{*}\left(S_{t}(\lambda)\right)=\frac{\int_{\lambda} S_{A}(\lambda) S_{r e l}(\lambda) d \lambda \int_{\lambda} S_{t}(\lambda) V(\lambda) d \lambda}{\int_{\lambda} S_{A}(\lambda) V(\lambda) d \lambda \int_{\lambda} S_{t}(\lambda) S_{r e l}(\lambda) d \lambda},
$$


where $S_{\mathrm{t}}(\lambda)$ is the relative retroreflected spectral power distribution, $S_{\mathrm{A}}(\lambda)$ is the relative spectral power distribution of CIE Illuminant $\mathrm{A}$, and $s_{\mathrm{rel}}(\lambda)$ is the relative response of the photometric system. The relative response of the photometric system is the same as $s(\lambda)$. Therefore, to make a corrected photometric measurement, the relative retroreflected spectral power distribution, $S_{\mathfrak{t}}(\lambda)$, needs to be measured. The quality of the spectrum required can be realized on a diode array system with reasonable stray light rejection. The magnitude of spectral mismatch correction factors can be as high as $5 \%$, but the uncertainty in the correction factor is typically less than $0.20 \%$.

The expected magnitude of the signal depends on the source flux, the coefficient of retroreflection, and the illuminance responsivity of the detector system. Section 2, which describes the source, suggests that based on calculations at least $100 \mathrm{~lm}$ will be projected from the sphere source system. For a $0.2 \mathrm{~m} \mathrm{x} 0.2 \mathrm{~m}$ sample, the projected image will be $0.40 \mathrm{~m}$ in diameter, which gives $795 \mathrm{~lx}$. The minimum signal-to-noise ratio that will be maintained for this system is at least $1000: 1$. Since the noise on the highest gain is $\approx 1 \mathrm{fA}$, the signal needs to be greater than $1 \mathrm{pA}$. The responsivity of the photometers without collection optics is typically $3 \mathrm{nA} / \mathrm{lx}$. The collection optics typically collect an aperture of $25 \mathrm{~mm}$ and focus the light to an aperture of $3 \mathrm{~mm}$, which is an increase in illumination of 69 times. However, due to reflections from the focusing optic and other considerations, the responsivity will be assumed to be $70 \mathrm{nA} / \mathrm{lx}$, therefore, $0.000015 \mathrm{~lx}$ is the minimum illuminance on the observer aperture. The observation distance is $30 \mathrm{~m}$, so the retroreflected luminous intensity must be $0.013 \mathrm{~cd}$. For a $0.2 \mathrm{~m} \mathrm{x} 0.2 \mathrm{~m}$ sample, the minimum coefficient of retroreflection that can be measured is $0.41[\mathrm{mcd} / 1 \mathrm{x}] / \mathrm{m}^{2}$. For a $120 \mathrm{~cm}$ long by $10 \mathrm{~cm}$ wide pavement marking strip, the projected source image will be $0.15 \mathrm{~m}$ in diameter, therefore, the minimum coefficient of line retroreflection is $0.07[\mathrm{mcd} / \mathrm{lx}] / \mathrm{m}$.

\subsection{SPECTRORADIOMETRIC DETECTION}

Currently, the specific requirements have not been determined for the spectroradiometer to be purchased. NIST has the luxury of borrowing a variety of spectroradiometers from diode array systems to double monochromator systems from internal facilities. By testing a variety of systems to determine the acceptable level of signal and colorimetric measurements uncertainties, the optimum system can be purchased at a later time. 


\section{ALIGNMENT}

The most critical aspect of the NIST Reference Retroreflectometer is the alignment of the three components: the source system, the goniometer and the detection system. The following sections describe the methods for aligning the components and the effect on the four angles used for defining the retroreflective system. The expected uncertainty from these alignment procedures is calculated in Sec. 6.

\subsection{ABSOLUTE OBSERVATION ANGLE ALIGNMENT}

The first axis that must be defined is the illumination axis. The illumination axis is defined as the axis from the retroreflector point of reference pointing to the source point of reference. The points of reference are defined as the center of the goniometer and the source aperture. A laser that has a telescope to minimize the divergence is aligned through the center of the source aperture, by using a detector and an aperture smaller than the waist of the laser beam. The alignment aperture is removed and the laser is aligned on a detector masked by a small aperture that is positioned at the retroreflector point of reference. This process is iterated until no further alignments to the laser are required. This procedure assumes that the rail system and the goniometer have been precisely aligned along the illumination axis, therefore, at any position along the rail system the laser is centered on the retroreflector point of reference. The laser is directed down the illumination axis by a kinematic mirror that can be removed and replaced to periodically check the alignment.

The next parameter to set is the position of the observer aperture. Ideally, if the observer aperture could be positioned in the same physical space as the source aperture, the encoders for the observation angle positioner could be measured and the observation angle equal to zero $(\alpha=0)$ would be determined. Since this is not physically possible, the observer aperture must be positioned in a known location and measured to determine its exact location. Figure 12 shows a drawing of the source and observer aperture holders. A variety of apertures sizes will be constructed to match the customers' requests. The important aspects of the aperture designs are the reference plane notches at the top of the holders, which are machined to be at the center of the aperture (to within $0.0025 \mathrm{~cm}$ ) and in the aperture plane (shown in the top view). A large prism attached to a solid partition on a manual translation stage will couple the source illumination to the source aperture.

The first stage to be set absolutely is the rotation stage. A second collimated laser is positioned behind the goniometer. The second laser propagates along the first laser in the opposite direction. A coated etalon, which is mounted to an aperture plate, is mounted in the observer aperture holder. Using an etalon optic ensures that the front and rear surfaces of the optic are as parallel as possible. The wedge for an etalon is less than 1 arc second $\left(0.0003^{\circ}\right)$. The observer aperture is positioned in front of the laser and the laser is reflected back upon itself. The rotation stage is set absolutely to $0^{\circ}$ to within the encoder uncertainty of $\pm 0.01^{\circ}$.

To calibrate the small stage, the observer aperture is positioned $5 \mathrm{~cm}$ behind the source aperture. The distance between the reference plane notches is measured by a micrometer. With this measurement, the small stage is absolutely calibrated for position to the uncertainty of its encoder $( \pm 0.01 \mathrm{~mm})$. To calibrate the long stage, the small stage positions the observer aperture such that the observation distance and the illumination distance are equal. The long stage moves the observer aperture $5 \mathrm{~cm}$ away from the source aperture, and the rotation stage moves to $0.10^{\circ}$. The distance 


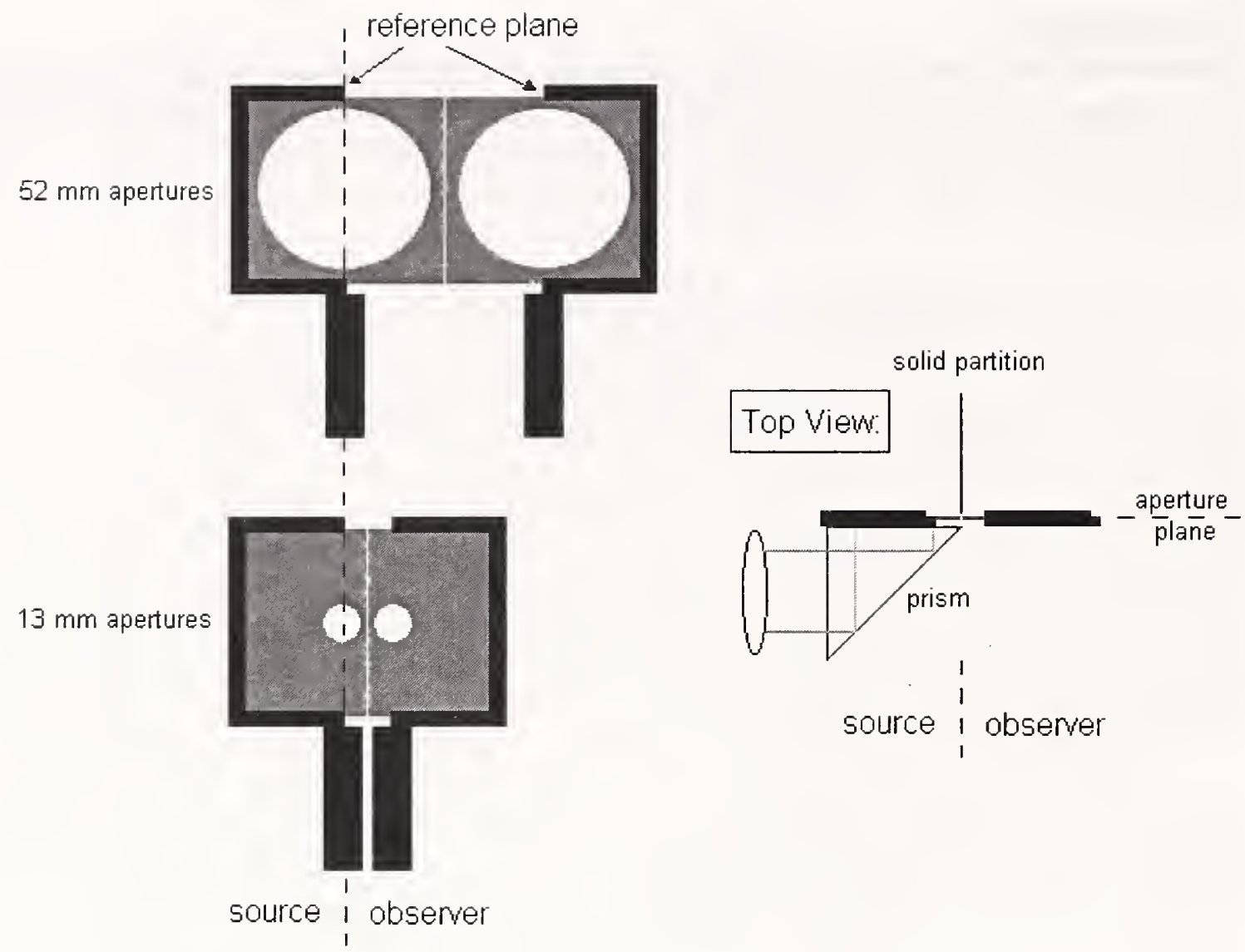

Figure 12 - Aperture Holders with Different Apertures

between the reference plane notches is measured by a micrometer. With this measurement the long stage is absolutely calibrated for position to the uncertainty of its encoder $( \pm 0.003 \mathrm{~mm})$.

The illumination distance is measured by a magnetic tape that is mounted to the goniometer and the rail system. The observation distance is initially set by the magnetic tape and the absolute position of the small stage. The observation distance is then calculated by the movement of the small, long, and rotation stages. By knowing the illumination distance, the observation distance and the aperture separation, the initial absolute observation angle can be calculated by the law of cosines to an uncertainty of $0.00033^{\circ}(k=2)$.

\subsection{ABSOLUTE ENTRANCE ANGLE COMPONENTS ALIGNMENT}

The absolute alignment of the entrance angle components, $\beta_{1}$ and $\beta_{2}$, relies on the laser that defines the illumination axis described in the previous section, Absolute Observation Angle Alignment. An aperture plate with a small hole is placed in the source aperture holder. A coated etalon or an alignment cube is mounted on the goniometer. The alignment cube will be used when measuring pavement marking material because it sets the entrance angle to $90^{\circ}$. The laser is reflected back upon itself by moving the entrance angle components of the goniometer. The entrance angle components are determined to be $0^{\circ}$ with an uncertainty of $0.0065^{\circ}(k=2)$.

\subsection{ABSOLUTE ROTATION ANGLE ALIGNMENT}

The absolute alignment of the rotation angle depends on the laser that defines the illumination axis described in the section Absolute Observation Angle Alignment. A quadrant detector is fastened to 


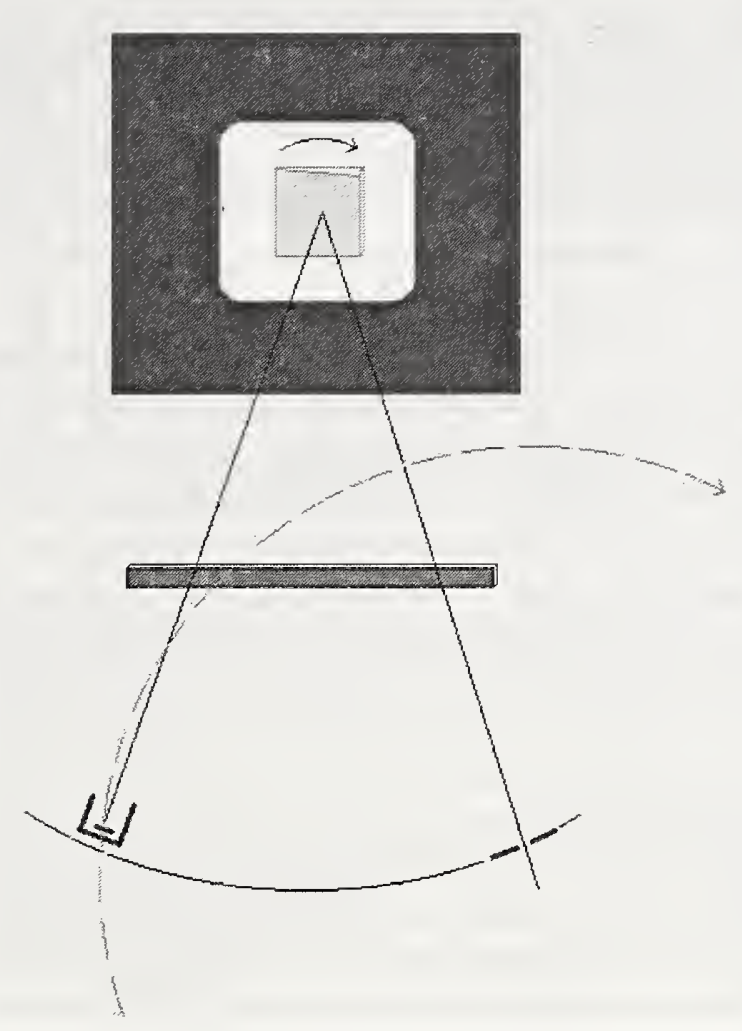

Figure 13 - Alignment of Rotation Angle

the observation angle positioner such that its height is the same as the illumination axis. The height is set by moving the detector in front of the illumination axis laser physically up or down. The quadrant detector is moved away from the illumination axis by $1.5 \mathrm{~m}$. A wedge is mounted on the center of the goniometer. The rotation angle is adjusted until the reflected laser light is at the same height as the illumination axis, which is the height of the quadrant detector, as shown in Figure 13. This alignment determines the observation half-plane to an uncertainty of $0.0082^{\circ}(k=2)$.

The second step in this alignment procedure is to transfer the observation half-plane to a straight edge. The straight edge is mounted on a table that sits on the rail system. A detector is placed on the table along the illumination axis. The straight edge is raised until half of the laser beam is blocked as determined by the intensity of the signal from the detector. The detector is removed and the straight edge is moved perpendicularly to the illumination axis to allow the laser beam to reflect off of the wedge and back toward the quadrant detector. The straight edge is then raised or lowered to block half the laser beam. This process is repeated until no further iterations are required.

The last step is to align four alignment telescopes to the straight edge. The telescopes will be mounted on a platform that is placed on the rail system and brought close to the retroreflective sample when it is mounted on the goniometer. Two telescopes will be separated by $15 \mathrm{~cm}$ and two will be separated by $30 \mathrm{~cm}$ for larger samples. Using the aligned telescopes the datum axis can be set along the observation half-plane. The procedure aligns the rotation angle of the retroreflector device to $-90^{\circ}$ with an uncertainty of $0.090^{\circ}(k=2)$, if the $15 \mathrm{~cm}$ telescopes are used and an uncertainty of $0.061^{\circ}(k=2)$, if the $30 \mathrm{~cm}$ telescopes are used. 


\subsection{EXPECTED UNCERTAINTY}

The overall uncertainty for the measurement of the coefficient of retroreflection has not been determined. The overall uncertainty is dependent on the source spectral distribution, the source stability, the source uniformity, the scattered light, the source and observer aperture sizes, the detector noise, the detector filter match to the $V(\lambda)$-function and the measurement of the area of the retroreflector device. Table 1 presents the expected uncertainty for each of these components. Probably most important is the positioning of the retroreflector device, which is described by the parameters $\left(\alpha, \beta_{1}, \beta_{2}\right.$, and $\left.\varepsilon\right)$ in the CIE Goniometer System. Therefore, a significant amount of effort has been placed on making the uncertainties as small as possible for these angles. Based on the alignment procedures described in Sec. 5, Alignment, the absolute uncertainty has been calculated and presented in the following sections. Also, presented is the uncertainty in the angles, $\omega_{s}, \gamma, a, b, e$, and $d$ for the other three systems presented: The Intrinsic System, The Application System, and The Road Marking System. The dependency of all these parameters is currently being modeled, but to determine the dependencies accurately the system needs to be completed and experiments performed.

Table 1 - Expected Uncertainty Factors

\begin{tabular}{|l|c|}
\hline Uncertainty Factor & Expected Uncertainty \% \\
\hline Source Stability & 0.025 \\
\hline Source Uniformity & 0.25 \\
\hline Scattered Light & 0.02 \\
\hline Source Aperture & 0.10 \\
\hline Detector Aperture & 0.10 \\
\hline Source Color Temperature & 0.10 \\
\hline Detector Filter Match & 0.25 \\
\hline Area Measurement & 0.25 \\
\hline
\end{tabular}

\subsection{ABSOLUTE UNCERTAINTY IN $\alpha$}

The uncertainty determination of the observation angle begins with setting the initial observation angle as described in the alignment procedure. By measuring the illumination distance, the observation distance and the separation between the source and observation apertures; and using the law of cosines, the initial observation angle can be determined as shown in the following equation:

$$
\alpha_{0}=\cos ^{-1}\left(\frac{s^{2}+d_{0}^{2}+c_{0}^{2}}{2 s d_{0}}\right),
$$

Here, $s$ is the illumination distance, $d_{0}$ is the initial observation distance and $c_{0}$ is the initial aperture separation. All of the details for determining the uncertainty in $\alpha_{0}$ are given Table 2. This table follows the procedure used in the "Guide to the Expression of Uncertainty in Measurement" (GUM) published by the International Organization for Standardization (ISO).[4] This Guide establishes general rules for evaluating and expressing uncertainty in measurement. 
Table 2 - Uncertainty budget for setting the initial observation angle absolutely

\begin{tabular}{|c|c|c|c|c|c|c|c|c|c|c|}
\hline No & $\begin{array}{c}\text { Quantity } \\
X_{\mathrm{i}} \\
\end{array}$ & Symbol & $\begin{array}{l}\text { Value } \\
\mathrm{x}_{\mathrm{i}} \\
\end{array}$ & $\begin{array}{c}\text { Standard } \\
\text { Uncertainty } \\
\mathbf{u}\left(\mathrm{x}_{\mathrm{i}}\right) \\
\end{array}$ & Unit & $\begin{array}{c}\text { Type of } \\
\text { eval. }\end{array}$ & $\begin{array}{c}\text { Deg. of } \\
\text { freedom } \\
v_{i} \\
\end{array}$ & $\begin{array}{c}\text { Sensitivity } \\
\text { Coefficient } \\
\mathrm{c}_{\mathrm{i}} \\
\end{array}$ & Unit & $\begin{array}{c}\text { Uncertainty } \\
\text { Contribution } \\
\mathrm{u}_{\mathrm{i}}(\mathrm{y}) / \mathrm{deg} \\
\end{array}$ \\
\hline 1 & Illumination Distance & $s$ & 30.00000 & 0.001000 & $\mathrm{~m}$ & B & $\infty$ & -0.00236 & $\mathrm{deg} / \mathrm{m}$ & -0.0000024 \\
\hline 2 & Observation Distance & $d_{0}$ & 30.00000 & 0.001010 & $\mathrm{~m}$ & B & $\infty$ & -0.00236 & $\mathrm{deg} / \mathrm{m}$ & -0.0000024 \\
\hline 3 & Aperture Separation & $c_{0}$ & 0.05236 & 0.000061 & $\mathrm{~m}$ & B & $\infty$ & 2.70095 & $\mathrm{deg} / \mathrm{m}$ & 0.0001642 \\
\hline & Observation angle, $\alpha_{0}$ & $\alpha_{0}$ & 0.10000 & & $\operatorname{deg}$ & & $>100$ & & & 0.00016 \\
\hline
\end{tabular}

Listed in the table are the dependent quantities for the final result, the symbol for these quantities, the value and the standard uncertainty, with a coverage factor of $k=1$, the unit of the quantity, the type of evaluation method, which is Type A for statistically based and Type B for all others, the degrees of freedom, which for a Type A measurement is typically the number of repetitions and the sensitivity coefficient, which is the partial derivative of the model or equation with respect to the quantity. The uncertainty contribution is the standard uncertainty times the sensitivity coefficient. The combined standard uncertainty is the sum of the squares of the uncertainty contributions. Therefore, the last line in the table gives the resultant, the unit and the combined uncertainty. Typically, uncertainties are expressed as an expanded uncertainty with a coverage factor, $k$. A coverage factor of 2 is similar to a confidence interval of $95.45 \%$ if the degrees of freedom are large.

The sensitivity coefficients for Table 2 are listed below:

$$
\begin{aligned}
& \frac{\partial \alpha_{0}}{\partial s}=\frac{d_{0}^{2}-s^{2}-c_{0}^{2}}{2 s^{2} d_{0} \sqrt{1-\left(\frac{d_{0}^{2}+s^{2}-c_{0}^{2}}{2 s d_{0}}\right)}} \\
& \frac{\partial \alpha_{0}}{\partial d_{0}}=\frac{s^{2}-d_{0}^{2}-c_{0}^{2}}{2 s d_{0}^{2} \sqrt{1-\left(\frac{d_{0}^{2}+s^{2}-c_{0}^{2}}{2 s d_{0}}\right)}} \\
& \frac{\partial \alpha_{0}}{\partial c_{0}}=\frac{s d_{0} \sqrt{1-\left(\frac{d_{0}^{2}+s^{2}-c_{0}^{2}}{2 s d_{0}}\right)}}{}
\end{aligned}
$$

Based on these expressions, the initial observation angle can be set to $0.10000^{\circ} \pm 0.00032^{\circ}(k=2)$. To determine the uncertainty in an arbitrary placement of the observation angle, the law of cosines is used again. The observation distance and the aperture separation are dependent on the movement of the small stage, the long stage and the rotation stage. The uncertainty of the 
Small $\alpha$

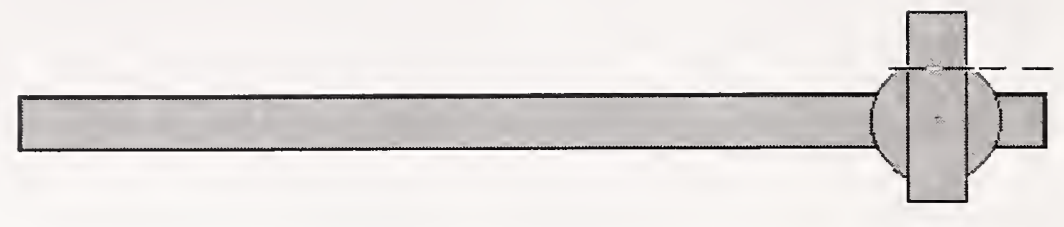

- source or detector aperture

Large $\alpha$

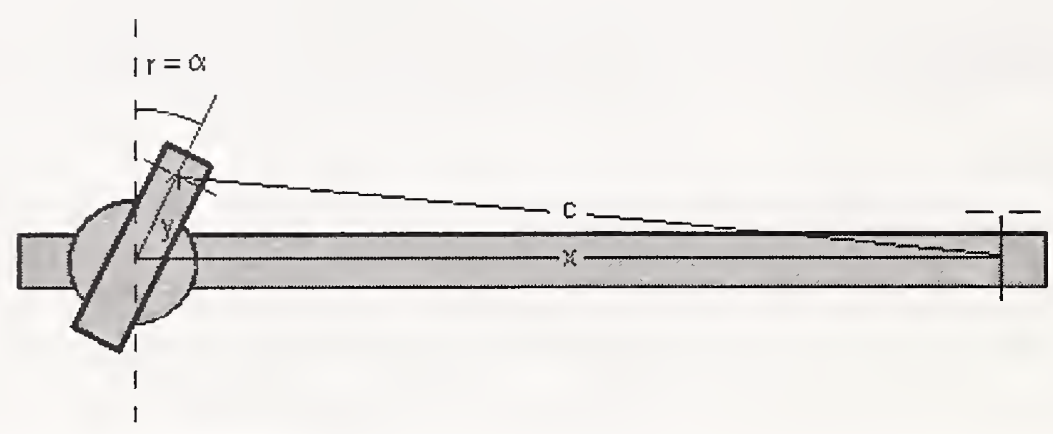

Figure 14 - Movements Along the Observation Angle Positioner

observation distance and aperture separation needs to be calculated. Figure 14 is a schematic of the movements of the stages. The following equation,

$$
c=\sqrt{y^{2}+x^{2}-2 x y \cos \left(90^{\circ}-r\right)}
$$

provides the aperture separation $\mathrm{c}$, where $\mathrm{x}$ is the change in distance along the long stage, $\mathrm{y}$ is the change in distance along the small stage and $r$ is the rotational change of the rotation stage. Table 3 shows the uncertainty budget for the aperture distance. The uncertainties for the movements include

Table 3 - Uncertainty budget for setting the aperture separation, $c$

\begin{tabular}{|c|c|c|c|c|c|c|c|c|c|c|}
\hline No & $\begin{array}{c}\text { Quantity } \\
\mathrm{X}_{1} \\
\end{array}$ & Symbol & $\begin{array}{c}\text { Value } \\
\mathrm{x}_{\mathrm{i}} \\
\end{array}$ & $\begin{array}{c}\text { Standard } \\
\text { Uncertainty } \\
\mathrm{u}\left(\mathrm{x}_{\mathrm{i}}\right) \\
\end{array}$ & Unit & $\begin{array}{c}\text { Type of } \\
\text { eval. }\end{array}$ & $\begin{array}{c}\text { Deg. of } \\
\text { freedom } \\
v_{i}\end{array}$ & $\begin{array}{c}\text { Sensitivity } \\
\text { Coefficient } \\
\mathrm{c}_{\mathrm{i}} \\
\end{array}$ & Unit & $\begin{array}{c}\text { Uncertainty } \\
\text { Contribution } \\
\mathrm{u}_{1}(\mathrm{y}) / \mathrm{m} \\
\end{array}$ \\
\hline 1 & Little Stage Movement & $y$ & 0.02399 & 0.000071 & $\mathrm{~m}$ & B & $\infty$ & 0.33923 & & 0.0000240 \\
\hline 2 & Long Stage Movement & $x$ & 1.20000 & 0.000064 & $\mathrm{~m}$ & B & $\infty$ & 1.41226 & & 0.0000901 \\
\hline 3 & Pointing Rotation & $r$ & 2.29061 & 0.010000 & deg & B & $\infty$ & -0.09405 & $\mathrm{~m} / \mathrm{deg}$ & -0.0000164 \\
\hline & Aperture Separation & $c$ & 1.19928 & & $\mathrm{~m}$ & & $>100$ & & & 0.00009 \\
\hline
\end{tabular}

$$
\frac{\partial c}{\partial y}=\frac{y-x \cos \left(90^{\circ}-r\right)}{\sqrt{c}} \quad \frac{\partial c}{\partial x}=\frac{x-y \cos \left(90^{\circ}-r\right)}{\sqrt{c}} \quad \frac{\partial c}{\partial r}=\frac{-x y \sin \left(90^{\circ}-r\right)}{\sqrt{c}}
$$


Table 4 - Uncertainty budget for observation distance, $d$

\begin{tabular}{|c|c|c|c|c|c|c|c|c|c|c|}
\hline No & $\begin{array}{c}\text { Quantity } \\
\mathrm{X}_{\mathrm{i}} \\
\end{array}$ & Symbol & $\begin{array}{r}\text { Value } \\
\mathrm{x}_{\mathrm{i}} \\
\end{array}$ & $\begin{array}{c}\text { Standard } \\
\text { Uncertainty } \\
\mathrm{u}\left(\mathrm{x}_{\mathrm{i}}\right) \\
\end{array}$ & Unit & $\begin{array}{l}\text { Type of } \\
\text { eval. }\end{array}$ & $\begin{array}{c}\text { Deg. of } \\
\text { freedom } \\
v_{\mathrm{I}} \\
\end{array}$ & $\begin{array}{c}\text { Sensitivity } \\
\text { Coefficient } \\
\mathrm{c}_{\mathrm{i}} \\
\end{array}$ & Unit & $\begin{array}{c}\text { Uncertainty } \\
\text { Contribution } \\
\mathrm{u}_{\mathrm{i}}(\mathrm{y}) / \mathrm{m}\end{array}$ \\
\hline 1 & Little Stage Movement & $y$ & 0.02399 & 0.000071 & $\mathrm{~m}$ & B & $\infty$ & -1.00000 & & -0.0000708 \\
\hline 2 & Long Stage Movement & $x$ & 1.20000 & 0.000064 & $\mathrm{~m}$ & B & $\infty$ & -0.00015 & & 0.0000000 \\
\hline 3 & Pointing Rotation & $r$ & 2.29061 & 0.010000 & deg & B & $\infty$ & 0.03498 & $\mathrm{~m} / \mathrm{deg}$ & 0.0000061 \\
\hline 4 & Illumination Distance & $s$ & 30.00000 & 0.001000 & $\mathrm{~m}$ & B & $\infty$ & 1.00222 & & 0.0010022 \\
\hline & Observation Distance & $\bar{d}$ & 30.00000 & & $\mathrm{~m}$ & & $>100$ & & & 0.00100 \\
\hline
\end{tabular}

$$
\begin{aligned}
& \frac{\partial d}{\partial y}=-1 \quad \frac{\partial d}{\partial x}=\sin (r)-\frac{x \cos (r)}{\sqrt{s^{2}-x^{2} \cos ^{2}(r)}} \\
& \frac{\partial d}{\partial r}=x \cos (r)+\frac{x^{2} \cos (r) \sin (r)}{\sqrt{s^{2}-x^{2} \cos ^{2}(r)}} \quad \frac{\partial d}{\partial s}=\frac{s}{\sqrt{s^{2}-x^{2} \cos ^{2}(r)}}
\end{aligned}
$$

the uncertainty determined in setting the initial observation angle. The following expression provides the observation distance $d$ :

$$
d=x \sin (r)-y+\sqrt{s^{2}-x^{2} \cos ^{2}(r)} .
$$

This equation comes from solving the law of cosines for $d$.

$$
s^{2}=(d+y)^{2}+x^{2}-2 x(d+y) \cos \left(90^{\circ}-r\right)
$$

In this case, the observation distance cannot be solved using a right triangle because the $90^{\circ}$ angle formed by the illumination axis and the long stage has uncertainty that is not accounted for in an equation using $d=x / \sin (r)-y$. Table 4 shows the uncertainty budget for the observation distance followed by the sensitivity coefficients.

With the uncertainties for the observation distance and the aperture separation the uncertainty for any arbitrary observation angle can be determined using the following equation:

$$
\alpha=\cos ^{-1}\left(\frac{s^{2}+d^{2}+c^{2}}{2 s d}\right) .
$$

Table 5 shows the uncertainty budget followed by the sensitivity coefficients. Therefore, for any arbitrary observation angle the absolute uncertainty will be $\pm 0.00057^{\circ}(k=2)$. 
Table 5 - Uncertainty budget for arbitrary setting of the observation angle

\begin{tabular}{|c|c|c|c|c|c|c|c|c|c|c|}
\hline No & $\begin{array}{c}\text { Quantity } \\
\qquad \mathrm{X}_{\mathrm{i}} \\
\end{array}$ & Symbol & $\begin{array}{r}\text { Value } \\
\mathrm{x}_{\mathrm{i}} \\
\end{array}$ & $\begin{array}{c}\text { Standard } \\
\text { Uncertainty } \\
\mathrm{u}\left(\mathrm{x}_{\mathrm{i}}\right) \\
\end{array}$ & Unit & $\begin{array}{c}\text { Type of } \\
\text { eval. }\end{array}$ & $\begin{array}{c}\text { Deg. of } \\
\text { freedom } \\
v_{\mathrm{I}} \\
\end{array}$ & $\begin{array}{c}\text { Sensitivity } \\
\text { Coefficient } \\
\mathrm{c}_{\mathrm{i}} \\
\end{array}$ & Unit & $\begin{array}{c}\text { Uncertainty } \\
\text { Contribution } \\
\mathrm{u}_{\mathrm{i}}(\mathrm{y}) / \mathrm{deg}\end{array}$ \\
\hline 1 & Illumination Distance & $s$ & 30.00000 & 0.001000 & $\mathrm{~m}$ & B & $\infty$ & -0.05399 & $\mathrm{deg} / \mathrm{m}$ & -0.0000540 \\
\hline 2 & Observation Distance & $d$ & 30.00000 & 0.001003 & $\mathrm{~m}$ & B & $\infty$ & -0.05399 & $\mathrm{deg} / \mathrm{m}$ & -0.0000542 \\
\hline 3 & Aperture Separation & $c$ & 1.19928 & 0.000102 & $\mathrm{~m}$ & B & $\infty$ & 2.70095 & $\mathrm{deg} / \mathrm{m}$ & 0.0002742 \\
\hline & Observation angle & $\alpha$ & 2.29061 & & $\operatorname{deg}$ & & $>100$ & & & 0.00028 \\
\hline
\end{tabular}

$$
\frac{\partial \alpha}{\partial s}=\frac{d^{2}-s^{2}-c^{2}}{2 s^{2} d \sqrt{1-\left(\frac{d^{2}+s^{2}-c^{2}}{2 s d}\right)}} \frac{\partial \alpha}{\partial d}=\frac{s^{2}-d^{2}-c^{2}}{2 s d^{2} \sqrt{1-\left(\frac{d^{2}+s^{2}-c^{2}}{2 s d}\right)}} \frac{\partial \alpha}{\partial c}=\frac{c}{s d \sqrt{1-\left(\frac{d^{2}+s^{2}-c^{2}}{2 s d}\right)}}
$$

\subsection{ABSOLUTE UNCERTAINTY IN $\beta, \beta_{1}$ and $\beta_{2}$}

The alignment procedure for the entrance angle components is straightforward. The uncertainty is reduced to the items used to calibrate, not procedural transfers or measured quantities. The following equation,

$$
\beta_{0}=C+L+G
$$

is used to model the absolute calibration of the entrance angle components, where $C$ is the angle of the alignment cube, $L$ is the angular contribution of the laser alignment procedure and $G$ is the angular contribution due to the goniometer. The uncertainties of the alignment cube, the laser alignment procedure and the goniometer encoder are additive in quadrature. Table 6 shows the uncertainty budget for setting the entrance angle components. The uncertainty of the alignment cube

\begin{tabular}{|c|c|c|c|c|c|c|c|c|c|c|}
\hline No & $\begin{array}{c}\text { Quantity } \\
\mathrm{X}_{\mathrm{i}} \\
\end{array}$ & Symbol & $\begin{array}{c}\text { Value } \\
\mathrm{x}_{\mathrm{i}} \\
\end{array}$ & $\begin{array}{c}\text { Standard } \\
\text { Uncertainty } \\
\mathrm{u}\left(\mathrm{x}_{\mathrm{i}}\right) \\
\end{array}$ & Unit & $\begin{array}{c}\text { Type of } \\
\text { eval. }\end{array}$ & $\begin{array}{c}\text { Deg. of } \\
\text { freedom } \\
v_{i} \\
\end{array}$ & $\begin{array}{c}\text { Sensitivity } \\
\text { Coefficient } \\
\mathrm{c}_{1} \\
\end{array}$ & Unit & $\begin{array}{c}\text { Uncertainty } \\
\text { Contribution } \\
\mathrm{u}_{1}(\mathrm{y}) / \mathrm{W} \\
\end{array}$ \\
\hline 1 & Alignment Cube & C & 0.00000 & 0.001155 & deg & $\mathrm{B}(\mathrm{R})$ & $\infty$ & 1.00000 & & 0.0011547 \\
\hline 2 & Laser Alignment & $L$ & 0.00000 & 0.000955 & $\operatorname{deg}$ & B & $\infty$ & 1.00000 & & 0.0009549 \\
\hline 3 & Goniometer Accuracy & G & 0.00000 & 0.002887 & deg & B (R) & $\infty$ & 1.00000 & & 0.0028868 \\
\hline & $\beta_{1}$ and $\beta_{2}$ angle & $\beta_{0}$ & 0.00000 & & deg & & $>100$ & & & 0.00325 \\
\hline
\end{tabular}

Table 6 - Uncertainty budget for setting entrance angle components, $\beta_{1}$ and $\beta_{2}$

$$
\frac{\partial \beta_{0}}{\partial C}=1 \quad \frac{\partial \beta_{0}}{\partial L}=1 \quad \frac{\partial \beta_{0}}{\partial G}=1
$$


Table 7 - Uncertainty budget for setting arbitrary entrance angle components, $\beta_{1}$ and $\beta_{2}$

\begin{tabular}{|c|c|c|c|c|c|c|c|c|c|c|}
\hline No & $\begin{array}{c}\text { Quantity } \\
\quad X_{i} \\
\end{array}$ & Symbol & $\begin{array}{l}\text { Value } \\
\mathrm{x}_{\mathrm{i}} \\
\end{array}$ & $\begin{array}{c}\text { Standard } \\
\text { Uncertainty } \\
\mathbf{u}\left(\mathrm{x}_{\mathrm{i}}\right) \\
\end{array}$ & Unit & $\begin{array}{c}\text { Type of } \\
\text { eval. }\end{array}$ & $\begin{array}{c}\text { Deg. of } \\
\text { freedom } \\
v_{i} \\
\end{array}$ & $\begin{array}{c}\text { Sensitivity } \\
\text { Coefficient } \\
\mathrm{c}_{\mathrm{i}} \\
\end{array}$ & Unit & $\begin{array}{c}\text { Uncertainty } \\
\text { Contribution } \\
\mathrm{u}_{\mathrm{i}}(\mathrm{y}) / \mathrm{W} \\
\end{array}$ \\
\hline 1 & $\beta_{\sharp}$ absolute & $\beta_{0}$ & 0.00000 & 0.003252 & $\operatorname{deg}$ & B & $\infty$ & 1.00000 & & 0.0032525 \\
\hline 2 & Change in $\beta_{\sharp}$ & $\Delta \beta$ & 30.00000 & 0.002887 & $\operatorname{deg}$ & B & $\infty$ & 1.00000 & & 0.0028868 \\
\hline & Entrance angle cor & $\beta_{*}$ & 30.00000 & & $\operatorname{deg}$ & & $>100$ & & & 0.00435 \\
\hline
\end{tabular}

$$
\frac{\partial \beta_{\sharp}}{\partial \beta_{0}}=1 \quad \frac{\partial \beta_{\sharp}}{\partial \Delta \beta}=1
$$

is $0.001155^{\circ}$ and the type of evaluation is $B(R)$, which stands for a Type $B$ evaluation derived from a rectangular distribution. The specifications on the alignment cube are $0.002^{\circ}$, which is a tolerance following a rectangular distribution. To approximate a rectangular distribution as a gaussian distribution, the tolerance is divided by the square root of three, as discussed in the GUM.

The setting of arbitrary entrance angle components is limited by the resolution of the goniometer as shown in the following expression and in Table 7 ,

$$
\beta_{\#}=\beta_{0}+\Delta \beta,
$$

where $\beta_{\sharp}$ stands for both entrance angle components and $\Delta \beta$ is the change in the entrance angle. For any arbitrary entrance angle components, the absolute uncertainty will be $\pm 0.0087^{\circ}$.

The entrance angle, $\beta$, is calculated from the equation,

$$
\beta=\cos ^{-1}\left(\cos \beta_{1} \cos \beta_{2}\right)
$$

and the uncertainty budget for $\beta$ is shown in Table 8 . The uncertainty fluctuates with the chosen values of the entrance angle components. The maximum uncertainty for the entrance angle is

\begin{tabular}{|c|c|c|c|c|c|c|c|c|c|c|}
\hline No & $\begin{array}{c}\text { Quantity } \\
\qquad \mathrm{X}_{\mathrm{i}}\end{array}$ & Symbol & $\begin{array}{r}\text { Value } \\
\mathrm{x}_{\mathrm{i}}\end{array}$ & $\begin{array}{c}\text { Standard } \\
\text { Uncertainty } \\
\mathrm{u}\left(\mathrm{x}_{\mathrm{i}}\right)\end{array}$ & Unit & $\begin{array}{c}\text { Type of } \\
\text { eval. }\end{array}$ & $\begin{array}{c}\text { Deg. of } \\
\text { freedom } \\
v_{i}\end{array}$ & $\begin{array}{c}\text { Sensitivity } \\
\text { Coefficient } \\
c_{i}\end{array}$ & Unit & $\begin{array}{c}\text { Uncertainty } \\
\text { Contribution } \\
\mathrm{u}_{\mathrm{i}}(\mathrm{y}) / \mathrm{deg}\end{array}$ \\
\hline 1 & Component & $\beta_{1}$ & 30.00000 & 0.004349 & deg & B & $\infty$ & 0.65465 & & 0.0028469 \\
\hline 2 & Component & $\beta_{2}$ & 30.00000 & 0.004349 & deg & B & $\infty$ & 0.65465 & & 0.0028469 \\
\hline & Entrance angle & $\beta$ & 41.40962 & & deg & & $>100$ & & & 0.00403 \\
\hline
\end{tabular}
$\pm 0.0087^{\circ}$.

Table 8 - Uncertainty budget for setting arbitrary entrance angle, $\beta$

$$
\frac{\partial \beta}{\partial \beta_{1}}=\frac{\left(\sin \beta_{1} \cos \beta_{2}\right)}{\sqrt{1-\left(\cos \beta_{1} \cos \beta_{2}\right)^{2}}} \quad \frac{\partial \beta}{\partial \beta_{2}}=\frac{\left(\sin \beta_{2} \cos \beta_{1}\right)}{\sqrt{1-\left(\cos \beta_{1} \cos \beta_{2}\right)^{2}}}
$$


Table 9 - Uncertainty budget for determining the Observation Half-Plane

\begin{tabular}{|c|c|c|c|c|c|c|c|c|c|c|}
\hline No & $\begin{array}{c}\text { Quantity } \\
\qquad \mathrm{X}_{\mathrm{i}} \\
\end{array}$ & Symbol & $\begin{array}{c}\text { Value } \\
\mathrm{x}_{i} \\
\end{array}$ & $\begin{array}{c}\text { Standard } \\
\text { Uncertainty } \\
\mathrm{u}\left(\mathrm{x}_{\mathrm{i}}\right)\end{array}$ & Unit & $\begin{array}{c}\text { Type of } \\
\text { eval. }\end{array}$ & $\begin{array}{c}\text { Deg. of } \\
\text { freedom } \\
v_{i} \\
\end{array}$ & $\begin{array}{c}\text { Sensitivity } \\
\text { Coefficient } \\
c_{i} \\
\end{array}$ & Unit & $\begin{array}{c}\text { Uncertainty } \\
\text { Contribution } \\
\mathrm{u}_{\mathrm{i}}(\mathrm{y}) / \mathrm{deg}\end{array}$ \\
\hline 1 & Aperture Separation & $c$ & 1.98682 & 0.000088 & $\mathrm{~m}$ & B & $\infty$ & 0.00000 & $\mathrm{deg} / \mathrm{m}$ & 0.0000000 \\
\hline 2 & Laser Alignment & $L$ & 0.00000 & 0.000100 & $\mathrm{~m}$ & B & $\infty$ & 28.83796 & $\mathrm{deg} / \mathrm{m}$ & 0.0028838 \\
\hline 3 & Goniometer Accuracy & $G$ & 0.00000 & 0.002887 & deg & $\mathrm{B}(\mathrm{R})$ & $\infty$ & 1.00000 & & 0.0028868 \\
\hline & Observation Half-Plane & $\varepsilon_{0}$ & 0.00000 & & deg & & $>100$ & & & 0.00408 \\
\hline
\end{tabular}

$$
\frac{\partial \varepsilon_{0}}{\partial c}=-L\left[c^{2}+L^{2}\right]^{-1} \quad \frac{\partial \varepsilon_{0}}{\partial L}=\left[c+\frac{L^{2}}{c}\right]^{-1} \quad \frac{\partial \varepsilon_{0}}{\partial G}=1
$$

\subsection{ABSOLUTE UNCERTAINTY IN $\varepsilon$}

The alignment procedure for the rotation angle has many transfers or steps. The first step is defining the observation half-plane. The uncertainty of the observation half-plane is based on a triangle defined by the aperture separation and the offset of the laser alignment along the vertical direction. The laser alignment along the vertical direction has a magnitude of zero, but an uncertainty of $0.1 \mathrm{~mm}$. The following equation,

$$
\varepsilon_{0}=\tan ^{-1}\left(\frac{L}{c}\right)+G,
$$

describes the tilt in the observation half-plane, where $L$ is the deviation in the vertical direction, which is zero, and $G$ is the calibration factor for the goniometer accuracy. Table 9 shows the uncertainty budget and the sensitivity coefficients for determining the observation half-plane.

The transfer step from the observation half-plane to the straight edge also relies on forming two triangles. The first triangle is dependent on aligning the straight edge to the lasers and the second triangle is based on the inherent uncertainty of the straight edge. The following model expresses the uncertainty in aligning the straight edge,

$$
S E=\tan ^{-1}\left(\frac{S A}{B S}\right)+\tan ^{-1}\left(\frac{S E_{0}}{B S}\right)+\varepsilon_{0},
$$

where $B S$ is the laser beam separation, $S A$ is the vertical deviation of setting the straight edge, which is equal to zero, and $S E_{0}$ is the vertical deviation of the straight edge due to the non-flatness. The straight edge has deviation from flatness of less than $0.0025 \mathrm{~cm}$ over the $1 \mathrm{~m}$ length. Table 10 shows the uncertainty budget for aligning the straight edge, followed by the sensitivity coefficients. 
Table 10 - Uncertainty budget for aligning the straight edge

\begin{tabular}{|c|c|c|c|c|c|c|c|c|c|c|}
\hline No & $\begin{array}{c}\text { Quantity } \\
\quad X_{i} \\
\end{array}$ & Symbol & $\begin{array}{c}\text { Value } \\
\mathrm{x}_{\mathrm{i}} \\
\end{array}$ & $\begin{array}{c}\text { Standard } \\
\text { Uncertainty } \\
\mathrm{u}\left(\mathrm{x}_{\mathrm{i}}\right) \\
\end{array}$ & Unit & $\begin{array}{c}\text { Type of } \\
\text { eval. }\end{array}$ & $\begin{array}{c}\text { Deg. of } \\
\text { freedom } \\
v_{i} \\
\end{array}$ & $\begin{array}{c}\text { Sensitivity } \\
\text { Coefficient } \\
\mathrm{c}_{\mathrm{i}} \\
\end{array}$ & Unit & $\begin{array}{c}\text { Uncertainty } \\
\text { Contribution } \\
\mathrm{u}_{1}(\mathrm{y}) / \mathrm{deg} \\
\end{array}$ \\
\hline 1 & Laser Beam Separation & BS & 1.00000 & 0.000036 & $\mathrm{~m}$ & B & $\infty$ & 0.00000 & $\mathrm{deg} / \mathrm{m}$ & 0.0000000 \\
\hline 2 & Straight Edge Alignment & $S A$ & 0.00000 & 0.000400 & $\mathrm{~m}$ & B & $\infty$ & 57.29578 & $\mathrm{deg} / \mathrm{m}$ & 0.0229183 \\
\hline 3 & Straight Edge Uncertainty & $S E_{0}$ & 0.00000 & 0.000051 & $\mathrm{~m}$ & B & $\infty$ & 57.29578 & $\mathrm{deg} / \mathrm{m}$ & 0.0029106 \\
\hline 4 & Observation Half-Plane & $\varepsilon_{0}$ & 0.00000 & 0.004080 & $\operatorname{deg}$ & B & $\infty$ & 1.00000 & & 0.0040804 \\
\hline & Straight Edge Angular Align & $S E$ & 0.00000 & & deg & & $>100$ & & & 0.02346 \\
\hline
\end{tabular}

$$
\frac{\partial S E}{\partial B S}=\frac{-S A}{\left(B S^{2}+S A^{2}\right)}+\frac{-S E_{0}}{\left(B S^{2}+S E_{0}^{2}\right)} \quad \frac{\partial S E}{\partial \varepsilon_{0}}=1
$$

$$
\frac{\partial S E}{\partial S A}=\frac{1}{\left(B S+\frac{S A^{2}}{B S}\right)} \quad \frac{\partial S E}{\partial S E_{0}}=\frac{1}{\left(B S+\frac{S E_{0}^{2}}{B S}\right)}
$$

The last step is to transfer the straight edge to the telescopes in the mount. Once again, the uncertainty of the transfer is based on triangles. Table 11 shows the uncertainty budget followed by the sensitivity coefficients for the model,

$$
\frac{\partial \varepsilon}{\partial T S}=\tan ^{-1}\left(\frac{T A}{T S}\right)+S E,
$$

where $T S$ is the telescope separation and $T A$ is the vertical deviation in aligning the telescopes. Therefore, the absolute uncertainty in the rotation angle will be $\pm 0.090^{\circ}(k=2)$ for the telescopes

\begin{tabular}{|c|c|c|c|c|c|c|c|c|c|c|}
\hline No & $\begin{array}{c}\text { Quantity } \\
\mathrm{X}_{\mathrm{i}} \\
\end{array}$ & Symbol & $\begin{array}{c}\text { Value } \\
\mathrm{x}_{\mathrm{i}} \\
\end{array}$ & $\begin{array}{c}\text { Standard } \\
\text { Uncertainty } \\
\mathrm{u}\left(\mathrm{x}_{\mathrm{i}}\right)\end{array}$ & Unit & $\begin{array}{c}\text { Type of } \\
\text { eval. }\end{array}$ & $\begin{array}{c}\text { Deg. of } \\
\text { freedom } \\
v_{i} \\
\end{array}$ & $\begin{array}{c}\text { Sensitivity } \\
\text { Coefficient } \\
\mathrm{c}_{1} \\
\end{array}$ & Unit & $\begin{array}{c}\text { Uncertainty } \\
\text { Contribution } \\
\mathrm{u}_{1}(\mathrm{y}) / \mathrm{deg} \\
\end{array}$ \\
\hline 1 & Telescope Separation & $T S$ & 0.15000 & 0.001000 & $\mathrm{~m}$ & B & $\infty$ & 0.00000 & $\operatorname{deg} / \mathrm{m}$ & 0.0000000 \\
\hline 2 & Telescope Alignment & $T A$ & 0.00000 & 0.000100 & $\mathrm{~m}$ & B & $\infty$ & 381.97186 & $\operatorname{deg} / m$ & 0.0381972 \\
\hline 3 & Straight Edge Angular Unc & $S E$ & 0.00000 & 0.023460 & deg & B & $\infty$ & 1.00000 & & 0.0234600 \\
\hline & Rotation Angle & $\varepsilon$ & 0.00000 & & deg & & $>100$ & & & 0.04483 \\
\hline
\end{tabular}
mounted at $15 \mathrm{~cm}$ and $\pm 0.061^{\circ}(k=2)$ for the telescopes mounted at $30 \mathrm{~cm}$.

Table 11 - Uncertainty budget for rotation angle, $\varepsilon$

$$
\frac{\partial \varepsilon}{\partial T S}=\frac{-T A}{\left(T S^{2}+T A^{2}\right)} \quad \frac{\partial \varepsilon}{\partial T A}=\frac{1}{\left(T S+\frac{T A^{2}}{T S}\right)} \quad \frac{\partial \varepsilon}{\partial S E}=1
$$


Table 12 - Uncertainty budget for orientation angle, $\omega_{\mathrm{s}}$

\begin{tabular}{|c|c|c|c|c|c|c|c|c|c|c|}
\hline No & $\begin{array}{l}\text { Quantity } \\
X_{i}\end{array}$ & Symbol & $\begin{array}{l}\text { Value } \\
\mathrm{x}_{\mathrm{i}} \\
\end{array}$ & $\begin{array}{c}\text { Standard } \\
\text { Uncertainty } \\
\mathrm{u}\left(\mathrm{x}_{\mathrm{i}}\right)\end{array}$ & Unit & $\begin{array}{c}\text { Type of } \\
\text { eval. }\end{array}$ & $\begin{array}{c}\text { Deg. of } \\
\text { freedom } \\
v_{i} \\
\end{array}$ & $\begin{array}{c}\text { Sensitivity } \\
\text { Coefficient } \\
c_{i} \\
\end{array}$ & Unit & $\begin{array}{c}\text { Uncertainty } \\
\text { Contribution } \\
\mathrm{u}_{\mathrm{i}}(\mathrm{y}) / \mathrm{deg}\end{array}$ \\
\hline 1 & Entrance Angle Component & $\beta_{1}$ & 45.00000 & 0.004349 & deg & B & $\infty$ & 0.00000 & & 0.0000000 \\
\hline 2 & Entrance Angle Component & $\beta_{2}$ & 0.00000 & 0.004349 & deg & B & $\infty$ & 1.00000 & & 0.0043488 \\
\hline 3 & Rotation Angle & $\varepsilon$ & 0.00000 & 0.044826 & deg & B & $\infty$ & 1.00000 & & 0.0448263 \\
\hline & Orientation Angle Uncertainty & $\omega_{\mathrm{s}}$ & 0.00000 & & deg & & $>100$ & & & 0.04504 \\
\hline
\end{tabular}

$$
\frac{\partial \omega_{s}}{\partial \beta_{1}}=\frac{-\sin \beta_{2}}{\sin ^{2} \beta_{1}}+\left(\cos \beta_{1} \sin \beta_{2}\right)^{2} \quad \frac{\partial \omega_{s}}{\partial \beta_{2}}=\frac{\cos \beta_{2}}{\left(\tan \beta_{1}+\frac{\sin ^{2} \beta_{2}}{\tan \beta_{1}}\right)} \quad \frac{\partial \omega_{s}}{\partial \varepsilon}=1
$$

\subsection{ABSOLUTE UNCERTAINTY IN CALCULATED ANGLES}

\subsubsection{Orientation Angle, $\omega_{s}$}

The orientation angle is the angle in a plane perpendicular to the retroreflector axis from the entrance half-plane to the datum axis. The orientation angle is used in the Intrinsic and the Application Systems. It is dependent on the rotation angle and the entrance angle components as shown in the equation,

$$
\omega_{s}=\varepsilon+\tan ^{-1}\left(\frac{\sin \beta_{2}}{\tan \beta_{1}}\right)+90^{\circ}\left[1-\operatorname{sgn}\left(\beta_{1}\right)\right]
$$

Table 12 shows a representative uncertainty budget for the orientation angle and the equations for the sensitivity coefficients. The orientation angle is not uniquely defined by three individual parameters. Figure 15 shows the dependence of the uncertainty on the entrance angle

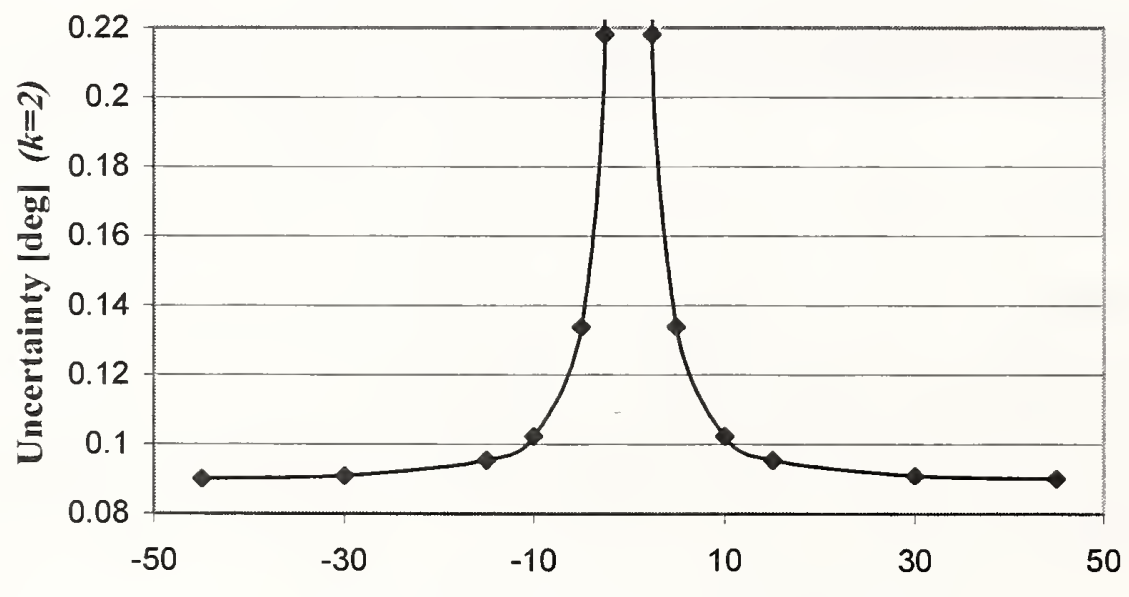

Entrance Angle Component, $\beta_{1}[\mathrm{deg}]$

Figure 15 - Orientation Angle Uncertainty Dependence 
component, $\beta_{1}$, when $\beta_{2}$ is equal to $0^{\circ}$. The orientation angle is set equal to zero by changing the rotation angle. The absolute uncertainty in the orientation angle varies from $\pm 0.090^{\circ}$ to infinity as $\beta_{1}$ approaches $0^{\circ}$. When $\beta$ approaches zero, the illumination axis and the retroreflector axes coincide. This is a special case, the definition of the entrance half-plane can no longer be applied. Therefore, by convention, $\omega_{\mathrm{s}}=0^{\circ}$. Another special case is when $\beta_{1}=0^{\circ} \neq \beta_{2}$. In this case the following equation applies:

$$
\omega_{s}=\varepsilon+90^{\circ} \operatorname{sgn}\left(\beta_{2}\right) .
$$

The uncertainty for the orientation angle is the same as that for the rotation angle, $\pm 0.090^{\circ}$. Given these special cases and the fact the uncertainty at small entrance angles increases significantly, more analysis needs to be performed.

\subsubsection{Presentation Angle, $\gamma$}

The presentation angle is the dihedral angle from the entrance half-plane to the observation halfplane, measured counter-clockwise from the viewpoint of the light source. The orientation angle is used in the Intrinsic System. It is dependent on the entrance angle components as shown in the equation,

$$
\gamma=\tan ^{-1}\left(\frac{\tan \beta_{2}}{\sin \beta_{1}}\right)
$$

Table 13 shows a representative uncertainty budget for the presentation angle and the equations for the sensitivity coefficients. The absolute uncertainty in the presentation angle varies from $\pm 0.009^{\circ}$ $(k=2)$ to infinity. When $\beta$ approaches zero, the illumination axis and the retroreflector axis coincide

\begin{tabular}{|c|c|c|c|c|c|c|c|c|c|c|}
\hline No & $\begin{array}{c}\text { Quantity } \\
\qquad \mathrm{X}_{\mathrm{i}} \\
\end{array}$ & Symbol & $\begin{array}{c}\text { Value } \\
\mathrm{x}_{\mathrm{i}} \\
\end{array}$ & $\begin{array}{c}\text { Standard } \\
\text { Uncertainty } \\
\mathrm{u}\left(\mathrm{x}_{\mathrm{i}}\right)\end{array}$ & Unit & $\begin{array}{c}\text { Type of } \\
\text { eval. }\end{array}$ & \begin{tabular}{|c|} 
Deg. of \\
freedom \\
$v_{i}$ \\
\end{tabular} & $\begin{array}{c}\text { Sensitivity } \\
\text { Coefficient } \\
c_{i} \\
\end{array}$ & Unit & $\begin{array}{c}\text { Uncertainty } \\
\text { Contribution } \\
\mathrm{u}_{\mathrm{i}}(\mathrm{y}) / \mathrm{deg} \\
\end{array}$ \\
\hline 1 & Entrance Angle Component & $\beta_{1}$ & 30.00000 & 0.004349 & $\operatorname{deg}$ & B & $\infty$ & -0.72111 & & -0.0031359 \\
\hline 2 & Entrance Angle Component & $\beta_{2}$ & 15.00000 & 0.004349 & deg & B & $\infty$ & 1.66533 & & 0.0072422 \\
\hline & Presentation Angle Uncertainty & $\gamma$ & 28.18679 & & deg & & $>100$ & & & 0.00789 \\
\hline
\end{tabular}

Table 13 - Uncertainty budget for presentation angle, $\gamma$

$$
\frac{\partial \gamma}{\partial \beta_{1}}=\frac{-\tan \beta_{2} \cos \beta_{1}}{\sin ^{2} \beta_{1}+\tan ^{2} \beta_{2}} \quad \frac{\partial \gamma}{\partial \beta_{2}}=\frac{\sin \beta_{1}}{\cos ^{2} \beta_{2} \sin ^{2} \beta_{1}+\sin ^{2} \beta_{2}}
$$




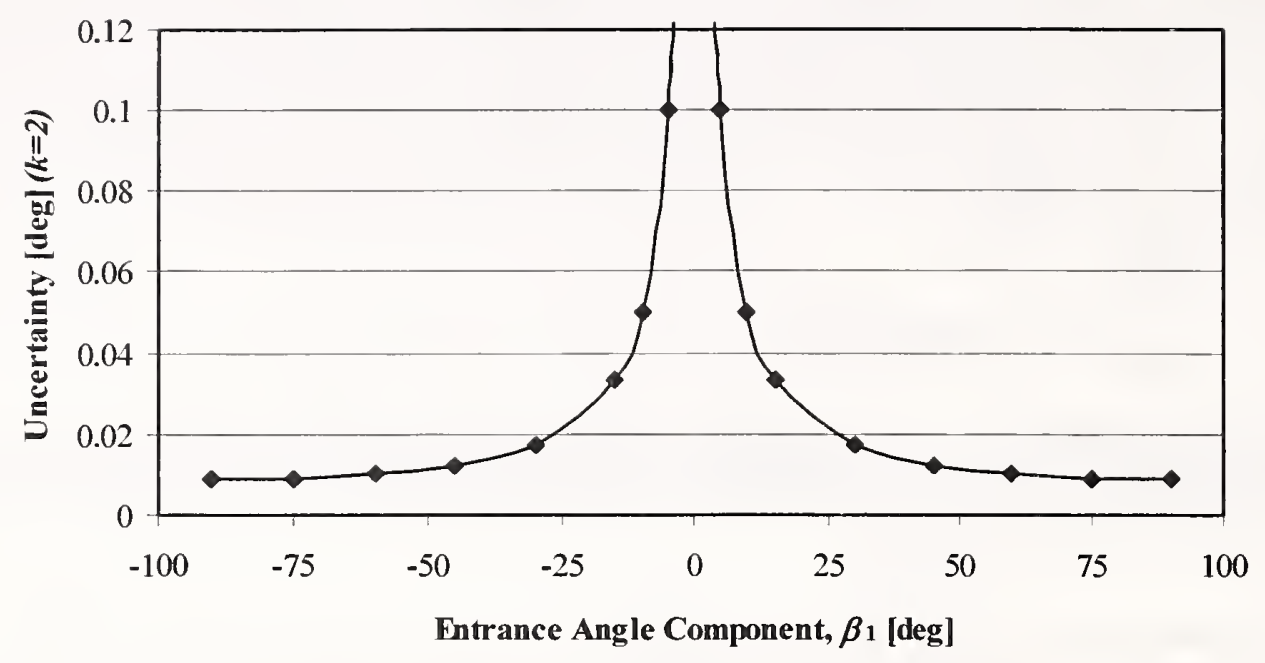

Figure 16 - Presentation Angle Uncertainty Dependence

causing the uncertainty to go to infinity as shown in Figure 16. Therefore, special cases exist. When $\beta_{1}=0^{\circ} \neq \beta_{2}$ the presentation angle reduces to,

$$
\gamma=90^{\circ} \operatorname{sgn}\left(\beta_{2}\right)
$$

and when $\beta_{1}=0^{\circ}=\beta_{2}$,

$$
\gamma=-\rho=-\varepsilon .
$$

Equation 19 implies that the presentation angle has no uncertainty in this special case, and eq. 20 shows that the uncertainty is equal to the uncertainty of the rotation angle, which is $\pm 0.090^{\circ}$. The real uncertainty lies between these limits, and further analysis is required to resolve this issue.

\subsubsection{Observation-Elevation Angle, $a$}

The observation-elevation angle is the complement of the angle between the retroreflector axis and the observation axis. The observation-elevation angle is used in the Road Marking System. For horizontal road markings, the retroreflector axis is considered to be normal to the road surface. Therefore, the observation-elevation angle is the angle the observation axis makes with the road surface. It is dependent on the entrance angle components and the observation angle as shown in the equation,

$$
a=\sin ^{-1}\left(\cos \left(\beta_{1}-\alpha\right) \cos \beta_{2}\right) .
$$

Table 14 shows the uncertainty budget for the observation-elevation angle and the equations for the sensitivity coefficients. The chosen entrance angle components and observation angles are based on an idealized vehicle and a viewing geometry of $30 \mathrm{~m}$. The absolute uncertainty in the observationelevation angle will be $\pm 0.0087^{\circ}(k=2)$. 
Table 14 - Uncertainty budget for observation-elevation angle, $a$

\begin{tabular}{|c|c|c|c|c|c|c|c|c|c|c|}
\hline No & $\begin{array}{c}\text { Quantity } \\
\mathrm{X}_{\mathrm{i}} \\
\end{array}$ & Symbol & $\begin{array}{r}\text { Value } \\
\mathrm{x}_{\mathrm{i}} \\
\end{array}$ & $\begin{array}{c}\text { Standard } \\
\text { Uncertainty } \\
\mathrm{u}\left(\mathrm{x}_{\mathrm{i}}\right) \\
\end{array}$ & Unit & $\begin{array}{c}\text { Type of } \\
\text { eval. }\end{array}$ & \begin{tabular}{|c|} 
Deg. of \\
freedom \\
$v_{\mathrm{i}}$ \\
\end{tabular} & $\begin{array}{c}\text { Sensitivity } \\
\text { Coefficient } \\
\mathrm{c}_{\mathrm{i}} \\
\end{array}$ & Unit & $\begin{array}{c}\text { Uncertainty } \\
\text { Contribution } \\
\mathrm{u}_{\mathrm{i}}(\mathrm{y}) / \mathrm{deg} \\
\end{array}$ \\
\hline 1 & Entrance Angle Component & $\beta_{1}$ & 88.76000 & 0.004349 & deg & B & $\infty$ & -1.00000 & & -0.0043488 \\
\hline 2 & Entrance Angle Component & $\beta_{2}$ & 0.00000 & 0.004349 & $\operatorname{deg}$ & B & $\infty$ & 0.00000 & & 0.0000000 \\
\hline 3 & Observation Angle & $\alpha$ & 1.05000 & 0.000285 & $\operatorname{deg}$ & B & $\infty$ & 0.99920 & & 0.0002844 \\
\hline & Observation-Elevation Angle & $a$ & 2.29000 & & $\operatorname{deg}$ & & $>100$ & & & 0.00436 \\
\hline
\end{tabular}

$$
\begin{gathered}
\frac{\partial a}{\partial \beta_{1}}=\frac{-\sin \left(\beta_{1}-\alpha\right) \cos \beta_{2}}{\sqrt{1-\cos ^{2}\left(\beta_{1}-\alpha\right) \cos ^{2} \beta_{2}}} \\
\frac{\partial a}{\partial \beta_{2}}=\frac{-\cos \left(\beta_{1}-\alpha\right) \sin \beta_{2}}{\sqrt{1-\cos ^{2}\left(\beta_{1}-\alpha\right) \cos ^{2} \beta_{2}}} \quad \frac{\partial a}{\partial \alpha}=\frac{\sin \left(\beta_{1}-\alpha\right) \cos \beta_{2}}{\sqrt{1-\cos ^{2}\left(\beta_{1}-\alpha\right) \cos ^{2} \beta_{2}}}
\end{gathered}
$$

\subsubsection{Road Marking First Azimuthal Angle, $b$}

The road marking first azimuthal angle is the dihedral angle from the half-plane originating on the line of the retroreflector axis and containing the obverse of the illumination axis to the half-plane originating on the line of the retroreflector axis and containing the observation axis, measured clockwise from a viewpoint on the retroreflector axis. It is dependent on the entrance angle components and the observation angle as shown in the equation,

$$
b=180^{\circ}+\operatorname{sgn}\left(\beta_{2}\right) \cos ^{-1}\left[\frac{\sin ^{2} \beta_{2} \cos \beta_{1} \cos \left(\beta_{1}-\alpha\right)+\sin \beta_{1} \sin \left(\beta_{1}-\alpha\right)}{\cos a \sqrt{1-\cos ^{2} \beta_{1} \cos ^{2} \beta_{2}}}\right] .
$$

Table 15 shows the uncertainty budget for the road marking first azimuthal angle and the equations for the sensitivity coefficients. The chosen entrance angle components and observation angles are equivalent to the $30 \mathrm{~m}$ geometry. The absolute uncertainty in the road marking first azimuthal angle

\begin{tabular}{|c|c|c|c|c|c|c|c|c|c|c|}
\hline No & $\begin{array}{c}\text { Quantity } \\
\mathrm{X}_{\mathrm{i}} \\
\end{array}$ & Symbol & $\begin{array}{l}\text { Value } \\
\mathrm{x}_{\mathrm{i}} \\
\end{array}$ & $\begin{array}{c}\text { Standard } \\
\text { Uncertainty } \\
\mathrm{u}\left(\mathrm{x}_{\mathrm{i}}\right) \\
\end{array}$ & Unit & $\begin{array}{l}\text { Type of } \\
\text { eval. }\end{array}$ & $\begin{array}{c}\text { Deg. of } \\
\text { freedom } \\
v_{i} \\
\end{array}$ & $\begin{array}{c}\text { Sensitivity } \\
\text { Coefficient } \\
\mathrm{c}_{i} \\
\end{array}$ & Unit & $\begin{array}{c}\text { Uncertainty } \\
\text { Contribution } \\
\mathrm{u}_{\mathrm{i}}(\mathrm{y}) / \mathrm{deg} \\
\end{array}$ \\
\hline 1 & Entrance Angle Component & $\beta_{1}$ & 88.76000 & 0.004349 & $\operatorname{deg}$ & B & $\infty$ & 1.23804 & & 0.0053840 \\
\hline 2 & Entrance Angle Component & $\beta_{2}$ & 0.00000 & 0.004349 & $\operatorname{deg}$ & B & $\infty$ & 0.00000 & & 0.0000000 \\
\hline 3 & Observation Angle & $\alpha$ & 1.05000 & 0.000153 & $\operatorname{deg}$ & B & $\infty$ & -1.58978 & & -0.0002437 \\
\hline 4 & Observation elevation angle & $a$ & 2.29000 & 0.004358 & deg & B & $\infty$ & -0.83476 & & -0.0036379 \\
\hline & RM First Azimuthal Angle & $b$ & 181.1785 & & deg & & $>100$ & & & 0.00650 \\
\hline
\end{tabular}
will be $\pm 0.013^{\circ}$.

Table 15 - Uncertainty budget for RM First azimuthal angle, $b$ 


$$
\frac{\partial b}{\partial \beta_{1}}=-\operatorname{sgn}\left(\beta_{2}\right) \frac{\left[\frac{\sin \left(2 \beta_{1}-\alpha\right)-\sin ^{2} \beta_{2} \sin \alpha}{\sqrt{1-\cos ^{2} \beta_{1} \cos ^{2} \beta_{2}}}-\frac{\cos \beta_{1} \sin \beta_{1} \cos \beta_{2}\left[\sin ^{2} \beta_{2} \cos \beta_{1} \cos \left(\beta_{1}-\alpha\right)+\sin \beta_{1} \sin \left(\beta_{1}-\alpha\right)\right]}{\sqrt[3]{1-\cos ^{2} \beta_{1} \cos ^{2} \beta_{2}}}\right]}{\cos a \sqrt{1-\frac{\left[\sin ^{2} \beta_{2} \cos \beta_{1} \cos \left(\beta_{1}-\alpha\right)+\sin \beta_{1} \sin \left(\beta_{1}-\alpha\right)\right]^{2}}{\cos ^{2} a\left(1-\cos ^{2} \beta_{1} \cos ^{2} \beta_{2}\right)}}}
$$

$\frac{\partial b}{\partial \beta_{2}}=-\operatorname{sgn}\left(\beta_{2}\right) \frac{\left[\frac{\sin ^{2} \beta_{2} \cos \beta_{1} \cos \left(\beta_{1}-\alpha\right)}{\sqrt{1-\cos ^{2} \beta_{1} \cos ^{2} \beta_{2}}}-\frac{\cos \beta_{1} \sin \beta_{2} \cos \beta_{2}\left[\sin ^{2} \beta_{2} \cos \beta_{1} \cos \left(\beta_{1}-\alpha\right)+\sin \beta_{1} \sin \left(\beta_{1}-\alpha\right)\right]}{\sqrt[3]{1-\cos ^{2} \beta_{1} \cos ^{2} \beta_{2}}}\right]}{\cos a \sqrt{1-\frac{\left[\sin ^{2} \beta_{2} \cos \beta_{1} \cos \left(\beta_{1}-\alpha\right)+\sin \beta_{1} \sin \left(\beta_{1}-\alpha\right)\right]^{2}}{\cos ^{2} a\left(1-\cos ^{2} \beta_{1} \cos ^{2} \beta_{2}\right)}}}$

$$
\frac{\partial b}{\partial \alpha}=-\operatorname{sgn}\left(\beta_{2}\right) \frac{\left[\frac{\sin ^{2} \beta_{2} \cos \beta_{1} \sin \left(\beta_{1}-\alpha\right)-\sin \beta_{1} \cos \left(\beta_{1}-\alpha\right)}{\cos a \sqrt{1-\cos ^{2} \beta_{1} \cos ^{2} \beta_{2}}}\right]}{\sqrt{1-\frac{\left[\sin ^{2} \beta_{2} \cos \beta_{1} \cos \left(\beta_{1}-\alpha\right)+\sin \beta_{1} \sin \left(\beta_{1}-\alpha\right)\right]^{2}}{\cos ^{2} a\left(1-\cos ^{2} \beta_{1} \cos ^{2} \beta_{2}\right)}}}
$$

$$
\frac{\partial b}{\partial a}=-\operatorname{sgn}\left(\beta_{2}\right) \frac{\left[\frac{\sin ^{2} \beta_{2} \cos \beta_{1} \cos \left(\beta_{1}-\alpha\right)+\sin \beta_{1} \sin \left(\beta_{1}-\alpha\right)}{\cos ^{2} a \sin a \sqrt{1-\cos ^{2} \beta_{1} \cos ^{2} \beta_{2}}}\right]}{\sqrt{1-\frac{\left[\sin ^{2} \beta_{2} \cos \beta_{1} \cos \left(\beta_{1}-\alpha\right)+\sin \beta_{1} \sin \left(\beta_{1}-\alpha\right)\right]^{2}}{\cos ^{2} a\left(1-\cos ^{2} \beta_{1} \cos ^{2} \beta_{2}\right)}}}
$$

\subsubsection{Illumination-Elevation Angle, $e$}

The illumination-elevation angle is the complement of the angle from the illumination axis to the retroreflector axis. The illumination-elevation angle is used in the Road Marking System. For horizontal road markings, the retroreflector axis is considered to be normal to the road surface. Therefore, the illumination-elevation angle is the angle the illumination axis makes with the road surface. It is dependent on the entrance angle components and the observation angle as shown in the equation,

$$
e=\sin ^{-1}\left(\cos \beta_{1} \cos \beta_{2}\right) .
$$

Table 16 shows the uncertainty budget for the illumination-elevation angle and the equations for the sensitivity coefficients. The chosen entrance angle components are equivalent to the $30 \mathrm{~m}$ geometry. The absolute uncertainty in the observation-elevation angle will be $\pm 0.0087^{\circ}(k=2)$. 
Table 16 - Uncertainty budget for Illumination Elevation angle, $e$

\begin{tabular}{|c|c|c|c|c|c|c|c|c|c|c|}
\hline No & $\begin{array}{l}\text { Quantity } \\
\mathrm{X}_{\mathrm{i}} \\
\end{array}$ & Symbol & $\begin{array}{c}\text { Value } \\
\mathrm{x}_{\mathrm{i}} \\
\end{array}$ & $\begin{array}{c}\text { Standard } \\
\text { Uncertainty } \\
\mathrm{u}\left(\mathrm{x}_{\mathrm{i}}\right)\end{array}$ & Unit & $\begin{array}{c}\text { Type of } \\
\text { eval. }\end{array}$ & $\begin{array}{c}\text { Deg. of } \\
\text { freedom } \\
v_{i} \\
\end{array}$ & $\begin{array}{c}\text { Sensitivity } \\
\text { Coefficient } \\
\mathrm{c}_{\mathrm{i}} \\
\end{array}$ & Unit & $\begin{array}{c}\text { Uncertainty } \\
\text { Contribution } \\
u_{i}(y) / \operatorname{deg} \\
\end{array}$ \\
\hline 1 & Entrance Angle Component & $\beta_{1}$ & 88.76000 & 0.004349 & $\operatorname{deg}$ & B & $\infty$ & -1.00000 & & -0.0043488 \\
\hline 2 & Entrance Angle Component & $\beta_{2}$ & 0.00000 & 0.004349 & deg & B & $\infty$ & 0.00000 & & 0.0000000 \\
\hline & Illumination Elevation Angle & $e$ & 1.24000 & & deg & & $>100$ & & & 0.00435 \\
\hline
\end{tabular}

$$
\frac{\partial e}{\partial \beta_{1}}=\frac{-\sin \beta_{1} \cos \beta_{2}}{\sqrt{1-\cos ^{2} \beta_{1} \cos ^{2} \beta_{2}}} \quad \frac{\partial e}{\partial \beta_{2}}=\frac{-\sin \beta_{2} \cos \beta_{1}}{\sqrt{1-\cos ^{2} \beta_{1} \cos ^{2} \beta_{2}}}
$$

\subsubsection{Road Marking Second Azimuthal Angle, $d$}

The road marking second azimuthal angle is the angle in the plane perpendicular to the retroreflector axis from the half-plane that originates on the line of the retroreflector axis and contains the observation axis, to the obverse of the datum axis, measured clockwise from a viewpoint on the retroreflector axis. It is dependent on the orientation angle and the road marking second azimuthal angle as shown in the equation,

$$
d=\omega_{s}+b-180^{\circ}
$$

Table 17 shows the uncertainty budget for the road marking second azimuthal angle and the equations for the sensitivity coefficients. The chosen orientation angle and road marking first azimuthal angles are equivalent to the $30 \mathrm{~m}$ geometry. The absolute uncertainty in the road marking second azimuthal angle will be $\pm 0.091^{\circ}(k=2)$. This uncertainty may be reduced if a better alignment procedure is created to align pavement markings along the rotation angle.

\begin{tabular}{|c|c|c|c|c|c|c|c|c|c|c|}
\hline No & $\begin{array}{l}\text { Quantity } \\
\mathrm{X}_{\mathrm{i}} \\
\end{array}$ & Symbol & $\begin{array}{c}\text { Value } \\
\mathrm{x}_{\mathrm{i}} \\
\end{array}$ & $\begin{array}{c}\text { Standard } \\
\text { Uncertainty } \\
\mathrm{u}\left(\mathrm{x}_{\mathrm{i}}\right) \\
\end{array}$ & Unit & $\begin{array}{c}\text { Type of } \\
\text { eval. }\end{array}$ & \begin{tabular}{|c} 
Deg. of \\
freedom \\
$v_{i}$ \\
\end{tabular} & $\begin{array}{c}\text { Sensitivity } \\
\text { Coefficient } \\
c_{i}\end{array}$ & Unit & $\begin{array}{c}\text { Uncertainty } \\
\text { Contribution } \\
\mathrm{u}_{\mathrm{i}}(\mathrm{y}) / \mathrm{deg}\end{array}$ \\
\hline 1 & Orientation Angle & $\omega_{\mathrm{s}}$ & 0.00000 & 0.045037 & $\operatorname{deg}$ & B & $\infty$ & 1.00000 & & 0.0450367 \\
\hline 2 & RM First Azimuthal Angle & $b$ & 0.00000 & 0.006502 & deg & B & $\infty$ & 1.00000 & & 0.0065024 \\
\hline & RM Second Azimuthal Angle & $d$ & 180.0000 & & deg & & $>100$ & & & 0.04550 \\
\hline
\end{tabular}

Table 17 - Uncertainty budget for RM Second Azimuthal angle, $d$

$$
\frac{\partial d}{\partial \omega_{s}}=1 \quad \frac{\partial d}{\partial b}=1
$$




\section{TRACEABILITY TO NIST}

The mission of NIST is to develop and promote measurement, standards, and technology to enhance productivity, facilitate trade, and improve the quality of life. To help meet the measurement and standards needs of retroreflective materials manufacturers and users, NIST provides calibrations, test methods, proficiency evaluation materials, measurement quality assurance programs, and laboratory accreditation services that assist customers in establishing traceability of results of measurements or values of standards.

Traceability requires the establishment of an unbroken chain of measurement comparisons to stated references. NIST assures the traceability of results of measurements or values of standards that NIST itself provides, either directly or through an official NIST program or collaboration. Other organizations are responsible for establishing the traceability of their own results or values to those of NIST or other stated references. The specific NIST policy statement is included in the next section to document the NIST role with respect to traceability. The section Establishing Traceability describes the specific requirements for an unbroken chain and an example of how NIST begins the chain. The Measurement Assurance Program is designed to determine how well a laboratory can measure retroreflectance. The NVLAP is a service that determines if a laboratory's competence and capability to provide scientifically sound and appropriate measurement services are within the scope of accreditation. Neither of these programs assures traceability to NIST. As part of this project a Measurement Assurance Program and a program within NVLAP will be initiated.

\subsection{STATEMENT OF POLICY}

To support the conduct of its mission and to ensure that the use of its name, products, and services is consistent with its authority and responsibility, NIST:

1. Adopts for its own use and recommends for use by others the definition of traceability provided in the most recent version of the International Vocabulary of Basic and General Terms in Metrology: "property of the result of a measurement or the value of a standard whereby it can be related to stated references, usually national or international standards, through an unbroken chain of comparisons all having stated uncertainties."[5]

2. Establishes traceability of the results of its own measurements and values of its own standards and of results and values provided to customers in NIST calibration and measurement certificates, operating in accordance with the NIST System for Assuring Quality in the Results of Measurements Delivered to Customers in Calibration and Measurement Certificates.

3. Asserts that providing support for a claim of traceability of the result of a measurement or value of a standard is the responsibility of the provider of that result or value, whether that provider is NIST or another organization; and that assessing the validity of such a claim is the responsibility of the user of that result or value.

4. Communicates, especially where claims expressing or implying the contrary are made, that NIST does not define, specify, assure, or certify traceability of the results of measurements or values of standards except those that NIST itself provides, either directly or through an official NIST program or collaboration.

5. Collaborates on development of standard definitions, interpretations, and recommended practices with organizations that have authority and responsibility for variously defining, specifying, assuring, or certifying traceability.

6. Develops and disseminates technical information on traceability and conducts coordinated outreach programs on issues of traceability and related requirements. 
7. Assigns responsibility for oversight of implementation of the NIST policy on traceability to the NIST Measurement Services Advisory Group.

\subsection{ESTABLISHING TRACEABILITY}

Traceability in regard to measurement is established through "an unbroken chain of comparisons all having stated uncertainties." In practical terms, for each link in the chain the following must be in place,

- A clear definition of the particular quantity that has been measured, in this case examples are coefficient of retroreflection or coefficient of line retroreflection

- A complete description of the measurement system used to perform the measurement

- A stated measurement result or value, with a documented uncertainty

- A complete specification of the stated reference at the time the measurement was performed, whether the calibrated artifact came directly from NIST or was supplied by another vendor that is traceable to NIST

- An 'internal measurement assurance' program for establishing the status of the measurement system at all times pertinent to the claim of traceability

- An 'internal measurement assurance' program for establishing the status of the stated reference at the time that the measurement system was performed.

Therefore, as an example, a NIST calibration report gives a brief description of the quantity measured, a description of the instrument used to measure the quantity, the value of the quantity measured along with a stated uncertainty and uncertainty budget, and a time frame of when the measurement device was last calibrated or the scale realized that it transfers. The full measurement description is published in an archival journal and is referenced in the calibration report. Also, behind the report is the NIST System for Assuring Quality in the Results of Measurements Delivered to Customers in Calibration and Measurement Certificates. The quality system provides a written set of documents to ensure a consistent methodology of calibration, which must exist and be reviewed regularly by NIST management.

The user of the result of a measurement or value of a standard is responsible for assessing the validity of a claim of traceability. The provider of the result of a measurement or value of a standard is responsible for supporting its claim of the traceability of that result or value. Thus, if a customer asks a provider for a complete chain of traceability, it is the provider who is responsible for providing the necessary information that the user assesses.

NIST will develop a calibration program where submitted artifacts will be calibrated for requested quantities, such as coefficient of retroreflection, coefficient of luminous intensity, or coefficient of line retroreflection. This calibration program will provide documentation of calibration, which includes the measurement value and the uncertainty associated with the measurement. The uncertainty is determined by an uncertainty budget, which is derived from characterizing the artifact. This calibration report begins the chain of traceability to NIST.

\subsection{MEASUREMENT ASSURANCE PROGRAM}

The purpose of the Measurement Assurance Program (MAP) is to determine the capabilities of a given laboratory and tie it to the National Standardization Program. This is achieved in a method that will simultaneously check measurements and procedures of the given laboratory by means of a package of various items to be measured. The MAP package may contain several types of 
retroreflectors that are chosen as diagnostic tools for certain aspects of a retroreflectometer. The measurement aspects range from geometrical capabilities to detection limits. The MAP package will likely contain filters that can be used to determine how well an instrument measures the luminous transmittance. The luminous transmittance provides spectral information on the source and detector capabilities. As NIST characterizes the reference retroreflectometer, tests will be added to the MAP package to diagnose the capabilities of other laboratories.

The final product of the MAP comparison is a report of calibration that is property of the given laboratory. The report contains: the Purpose of the Report, the Materials used in the Comparison, the Measurement Procedures of NIST and Instrument Description of the NIST Reference Retroreflectometer, the Results which show the measurements at NIST before and after the laboratory made its measurements, and the Conclusions derived from these measurements. Through the Measurement Assurance Program, a given laboratory can receive more assistance and interaction than by obtaining a calibrated artifact from NIST. As part of this project, development of a Measurement Assurance Program will begin for the measurement of various retroreflectance quantities.

\subsection{NATIONAL VOLUNTARY LABORATORY ACCREDITATION PROGRAM}

The NVLAP is an accreditation body operated by NIST. Laboratory accreditation is a finding of a laboratory's competence and capability to provide scientifically sound and appropriate measurement services within their scope of accreditation. Embedded in the process is an evaluation of the laboratory's ability to achieve and maintain traceability for the accredited services. Accreditation to ISO/IEC 17025: General requirements for the competence of testing and calibration laboratories determines that a laboratory has all of the necessary facilities, equipment, standards, procedures, uncertainty analyses, personnel, etc., which make it capable of providing traceable measurement results.[6] Laboratory accreditation does not speak to the specifics of any individual measurement result but to the overall capability of a lab to provide the service.

As part of this project, NIST will investigate and begin to develop an accreditation program with NVLAP. In developing a program the following items must be accomplished:

- Identify laboratory community

- Identify laboratory user community

- Identify standards writing bodies

- Identify test methods and standards

- Identify product certification/validation programs

- Identify regulatory bodies, both domestic and foreign

- Identify other stakeholders

- Identify sources of technical expertise and assistance - domestic and foreign

- Identify number of labs and amount of calibrations

- Select the "units" of the Scope of Accreditation

- Establish specific technical requirements

- Establish laboratory staff qualifications and certifications

- Establish components of a laboratory: equipment, facilities, ...

- Establish accreditation process sequence

- Develop the assessment techniques for on-sites, demonstrations, ...

- Design proficiency testing programs 
- Set on-site team size and skill set

- Create NVLAP program-specific checklists

- Establish evaluation criteria for granting of accreditation

- Establish fee schedule

- Determine contents of the NVLAP application package

- Publish Federal Register announcement

- Set time window for accepting initial applications, then no restrictions.

A number of these items have been accomplished. A number have been investigated. The remaining items will be developed, if the need for an accreditation program is perceived. With the development of the CIPM Mutual Recognition Arrangement (MRA) that was drawn up by the International Committee of Weights and Measures (CIPM) under the authority given to it in the Metre Convention, the need for a NVLAP program will become necessary for any international trade. The principal objectives of the MRA are to establish through measurement comparisons the degree of equivalence of national measurement standards maintained by National Metrology Institutes (NMIs), to provide for the mutual recognition of calibration and measurement certificates issued by NMIs, and to provide a secure technical foundation for wider agreements related to international trade, commerce, and regulatory affairs. 


\section{ACKNOWLEDGMENTS}

The research reported herein was performed under NCHRP Project $05-16$ by the Optical Technology Division, National Institute of Standards and Technology, Department of Commerce, United States Government, and Dr. Todd Heimer. The work undertaken by Dr. Heimer was under contract with the National Institute of Standards and Technology.

Dr. C. Cameron Miller, Research Chemist, National Institute of Standards and Technology, is the principal investigator. The other authors of this report are Dr. Edward Early, Physicist, National Institute of Standards of Technology and Dr. Todd Heimer.

The work was done under the general supervision of Dr. Yoshi Ohno; Dr. Keith Lykke, leader of the Detector Calibration Group in the Optical Technology Division; Dr. Gerald Fraser, leader of the Optical Thermometry Group in the Optical Technology Division; and Dr. Albert Parr, chief of the Optical Technology Division. 


\section{APPENDIX A Bibliography of Documentary Retroreflection Standards}

Document No.

A-A-251

AASHTO T257

AASHTO M268

ASTM D 4061

ASTM D 4280

ASTM D 4383

ASTM D 4956

ASTM D 6359

ASTM E 808

ASTM E 809

ASTM E 810

ASTM E 811

ASTM E 1501

ASTM E 1696

ASTM E 1709

ASTM E 1710

ASTM E 1743

ASTM E 1809

BS AU 145D

CIE 54.2-2001

CNS Z 8015

DIN 67520-1

EN 1463-1

EN 1463-2

FAA AC 150/5345-39

FED-STD-370

FED-STD-373

JIS Z8714

JIS Z9117

SAA AS 1906.1

SAA AS 1906.2

SAA AS 1906.3

SAA AS/NZS 1906.4

SAE J1967
Title

Retroreflective Tape and Retroreflective Sheeting

Standard Method of Test for Instrumental Photometric Measurement

Standard Specification for Retroreflective Sheeting for Traffic Control

Test Method for Retroreflectance of Horizontal Coatings

Specification for Extended Life Type, Non-plowable, Prismatic, Raised Retroreflective

Pavement Markers

Specification for Plowable, Raised Retroreflective Pavement Markers

Standard Specification for Retroreflective Sheeting for Traffic Control

Standard Specification for Minimum Retroreflectance of Newly Applied Pavement Marking Using Portable Hand-Operated Instruments

Standard Practice for Describing Retroreflection

Standard Practice for Measuring Photometric Characteristics of Retroreflectors

Standard Test Method of Coefficient of Retroreflection of Retroreflective Sheeting

Standard Practice for Measuring Colorimetric Characteristics of Retroreflectors Under

Nighttime Conditions

Standard Specification for Nighttime Photometric Performance of Retroreflective Pedestrian Markings for Visibility Enhancement

Standard Test Method for Field Measurement of Raised Retroreflective Pavement Markers Using a Portable Retroreflectometer

Standard Test Method for Measurement of Retroreflective Signs Using a Portable Retroreflectometer

Standard Test Method for Measurement of Retroreflective Pavement Marking Materials Standard Practice for Selection and Use of Portable Retroreflectometers for the Measurement of Pavement Marking Materials

Standard Test Method for Measurement of High-visibility Retroreflective Clothing Marking Material Using a Portable Retroreflectometer

Retroreflecting Number Plates

Retroreflection Definition and Measurement

Method of Test for Retroreflective Sheeting and Tape

Retroreflecting Materials for Traffic Safety

Road Marking Materials - Retroreflecting Road Studs - Part 1. Initial Performance

Requirements

Road Marking Materials - Retroreflecting Road Studs - Part 1. Road Test Performance Specifications

Spec/L-853 Runway and Taxiway Retroreflective Markers

Instrumental Photometric Measurements/Retroreflection

Instrumental Color Measurements of Retroreflective Materials and Devices Under Nighttime Illumination

Retroreflectors - Optical Properties - Measuring Method

Retroreflective Sheeting and Tape for Safety

Retroreflective Materials and Devices for Road Traffic Control Purposes

Retroreflective Devices (Non-pavement Application)

Raised Pavement Markers (Retroreflective and Non-retroreflective)

Retroreflective Materials and Devices for Road Traffic Control Purposes - High Visibility

Materials for Safety Garments

Retroreflective Materials for Vehicle Conspicuity 


\section{APPENDIX B Source Flux and Throughput Calculations}

\section{Flux and throughput of the Strip Lamp System}

To calculate the expected flux and throughput of the strip lamp system, the radiance of the tungsten strip needs to be calculated assuming it acts like a blackbody. The radiance is,

$$
L_{b b \lambda}=\frac{2 h c^{2}}{\lambda^{5}\left(e^{h c / \lambda h T}-1\right)}
$$

$$
\left[\frac{W}{m^{2} \cdot \mu m \cdot s r}\right]
$$

where $\mathrm{h}$ is Plank's constant, $6.62606876 \times 10^{-34} \mathrm{~J} \cdot \mathrm{s}, \mathrm{c}$ is the speed of light, $2.99792458 \times 10^{8} \mathrm{~m} / \mathrm{s}, \mathrm{k}$ is the Boltzmann constant, $1.3806503 \times 10^{-23} \mathrm{~J} / \mathrm{K}$ and $\mathrm{T}$ is the temperature of the blackbody, $2856 \mathrm{~K}$. Convolving the radiance curve with the $V(\lambda)$-function and integrating over the visible wavelength interval gives:

$$
L_{b b}=1.27898 \times 10^{7}
$$

$$
\left[\frac{l m}{m^{2} \cdot s r}\right] \text {. }
$$

The solid angle collection of the aspheric in this system is $1.77 \mathrm{sr}$, and the spot size of the image on the tungsten strip is $0.833 \mathrm{~mm}$ in diameter. The $5 \mathrm{~mm}$ aperture limits the spot size on the tungsten strip. The aspheric lens and the projection lens are not anti-reflection coated so the transmission is about 0.92 for each lens. Therefore, the flux making it to the source aperture is $10.45 \mathrm{~lm}$ for the strip lamp system.

\section{Flux and throughput of Sphere Projection System}

To calculate the expected flux and throughput of the sphere projection system, the luminance of the sphere needs to be calculated. The luminance of the sphere can be determined by,

$$
L_{s}=\frac{\Phi_{i}}{\pi A_{s}} \frac{\rho}{1-\rho(1-f)}
$$

$$
\left[\frac{l m}{m^{2} \cdot s r}\right]
$$

where $\Phi_{i}$ is the luminous flux coupled into the sphere, $\mathrm{A}_{\mathrm{s}}$ is the surface area of the sphere wall, $\rho$ is the luminous reflectance of the sphere wall, and $f$ is the port fraction[7]. The port fraction is calculated by,

$$
f=\frac{A_{i}+A_{e}}{A_{s}},
$$

where $A_{i}$ is the area of the entrance port and $A_{e}$ is the area of the exit port. The sphere is $5 \mathrm{~cm}$ in diameter and the entrance and exit ports are $1 \mathrm{~cm}$ in diameter giving a port fraction of 0.020 , which is less than the 0.050 maximum value suggested to maintain a good uniform source. The luminous reflectance of the sphere wall should be at least 0.95 .

The luminous flux coupled into the sphere will come from a $1000 \mathrm{~W}$ FEL lamp operated to produce a $2856 \mathrm{~K}$ blackbody distribution coming out of the sphere. The lamp will be at the focus of an elliptical mirror that couples the light to the entrance port. A second elliptical will face the first 
elliptical mirror to capture additional light and focus it to the entrance port. The $1000 \mathrm{~W}$ FEL lamp will produce about $18,000 \mathrm{~lm}$ and the coupling efficiency is expected to be about $75 \%$, therefore the luminous flux entering the sphere is $13,500 \mathrm{~lm}$. Entering these values into equation B-3 produces a luminance of,

$$
L_{s}=7.5330 \times 10^{6}
$$$$
\left[\frac{l m}{m^{2} \cdot s r}\right] \text {. }
$$

The area of the exit port is $7.854 \times 10^{-5} \mathrm{~m}^{2}$ and the solid angle collection using the aspheric lens is $2.6 \mathrm{sr}$. Therefore, the flux put through the aspheric lens is $1400 \mathrm{~lm}$. For this system an additional three lenses are required reducing the expected flux hitting the source aperture to $1090 \mathrm{~lm}$. This flux level and the expected uniformity would be significantly better than the other suggested systems. Even if this system produces one-tenth the expected flux, it will be a success. 


\section{REFERENCES}

[1] Ohno, Y., NIST Special Publication 250-37, "Photometric Calibrations" National Institute of Standards and Technology, Optical Technology Division, Gaithersburg, MD. (1997).

[2] Eppeldauer, G.P., Ed. NIST Technical Note 1438, "Optical Radiation Measurement with Selected Detectors and Matched Electronic Circuits Between $200 \mathrm{~nm}$ and $20 \mu \mathrm{m}$." National Institute of Standards and Technology, Optical Technology Division, Gaithersburg, MD. (2001).

[3] Thompson, A. and Chen. H., "Beamcon III, a Linearity Measurement Instrument for Optical Detectors," J. Res. NIST, Vol. 99, No. 6 (1994) p. 751-755.

[4] "Guide to the Expression of Uncertainty in Measurement," International Organization for Standardization, Geneva, Switzerland, First Edition, (1995)

[5] "International Vocabulary of Basic and General Terms in Metrology," Definition 6.10, International Organization for Standardization, Geneva, Switzerland, First Edition, (1993).

[6] "General requirements for the competence of testing and calibration laboratories," ISO/IEC 17025, International Organization for Standardization, Geneva, Switzerland, First Edition, (1999).

[7] Labsphere Techguide, "A Guide to Integrating Sphere Theory and Applications." Labsphere, Inc., North Sutton, NH. 

